\title{
Evidências de Pass-Through Incompleto da Taxa de Juros, Crédito Direcionado e Canal de Custo da Política Monetária no Brasil
}

\author{
Igor Ézio Maciel Silva ${ }^{1}$ \\ Nelson Leitão Paes $^{2}$ \\ Jocildo Fernandes Bezerra ${ }^{3}$
}

\begin{abstract}
Resumo
O objetivo deste artigo é analisar a relevância do canal de custo da política monetária no Brasil, a possibilidade de pass-through incompleto da taxa de juros, e a relação entre o crédito direcionado e a política monetária. Para tanto, elaborou-se um modelo DSGE Novo-Keynesiano, no qual: o custo das firmas é diretamente influenciado pelo nível da taxa de juros cobrada pelos bancos; uma parcela dos bancos não é capaz de modificar as taxas de juros que cobram pelos empréstimos a cada período; e, uma parcela dos bancos opera linhas de crédito direcionado. O modelo foi estimado por meio do método da distância mínima (Matching). Os resultados indicam que (i) o canal de custo desempenha papel relevante na transmissão da política monetária (explicando o price-puzzle da política monetária); (ii) não há evidência de pass-through incompleto; e (iii) o crédito direcionado reduz a capacidade de a política monetária modificar as condições de crédito.
\end{abstract}

\section{Palavras-Chave}

Política Monetária. Canal de Custo. Pass-Through da Taxa de Juros. Crédito Direcionado.

\begin{abstract}
The aim of this study is to analyze the relevance of the cost channel of monetary policy in Brazil, the possibility of a limited interest rate pass-through, and the relation among directed credit and monetary policy. For that, we use a New-Keynesian DSGE model in which: the costs of

- Os autores agradecem as críticas e sugestões dos pareceristas e, em especial, do professor Oliver Hülsewig (Munich University of Applied Sciences e Ifo Institute for Economic Research).

1 Professor - Programa de Pós-Graduação em Economia - Universidade Federal do Rio Grande do Norte (UFRN) Endereço: Av. Senador Salgado Filho, 3000 - Natal/RN - Brasil - CEP: 59078-970 E-mail: igormacielsilva@gmail.com - https://orcid.org/0000-0002-4809-008X.

2 Professor - Programa de Pós-Graduação em Economia - Universidade Federal de Pernambuco (UFPE) Endereço: Av. Prof. Moraes Rego, 1235, Cid. Universitária - Recife/PE - Brasil - CEP: 50670-420 E-mail: nlpaes@gmail.com - https://orcid.org/0000-0001-6246-4503.

3 Professor - Programa de Pós-Graduação em Economia - Universidade Federal de Pernambuco (UFPE) Endereço: Av. Prof. Moraes Rego, 1235, Cid. Universitária - Recife/PE - Brasil - CEP: 50670-420 E-mail: jocildo.bezerra@gmail.com - https://orcid.org/0000-0003-2623-5556.
\end{abstract}

Recebido: 11/01/2017. Aceite: 07/06/2018.

(c) (i) (\$) Esta obra está licenciada com uma Licença Creative Commons Atribuição-Não Comercial 4.0 Internacional. 
firms are directly influenced by the level of the banks' loan rate; part of banks are not able to adjust their loan rates each period; part of banks concede directed credit. We apply the minimum distance approach (Matching) as the estimation method. The results indicate that: the cost channel plays a decisive role in the monetary policy transmission, explaining the monetary policy price-puzzle; there is no evidence of incomplete interest rate pass-through; the directed credit reduces the monetary policy capacity to modify credit conditions.

\section{Keywords}

Monetary Policy. Cost Channel. Interest Rate Pass-Through. Directed Credit.

\section{JEL Classification}

C32. E44. E52.

\section{Introdução}

Uma literatura crescente tem incorporado a possibilidade de a política monetária afetar não apenas a demanda agregada, como também variáveis econômicas do lado da oferta (Gaiotti e Secchi 2006). Pelo menos dois tipos de evidência apontam para esse sentido. O primeiro deles é o pricepuzzle da política monetária (a resposta positiva da inflação a um choque de política monetária contracionista) encontrado em diversos estudos que aplicaram a metodologia dos Vetores Autorregressivos (VAR). O segundo tipo relaciona-se ao nível de amplificação dos choques, mais especificamente, choques de política monetária que induzem movimentos leves e transitórios nas taxas de juros, alteram o produto de modo considerável e persistente (Barth e Ramey 2002).

Uma explicação de como a política monetária opera pelo lado da oferta é fornecida pelo canal de custo. Por esse mecanismo de transmissão, alguns custos de produção crescem com a taxa de juros, e, portanto, uma política monetária contracionista pode promover um crescimento nos preços ao invés de uma redução (Rabanal e Rubio-Ramírez 2007).

O presente estudo tem por objetivo analisar a relevância do canal de custo da política monetária no Brasil. Para tanto, estima-se um modelo DSGE Novo-Keynesiano que é uma versão modificada daquele proposto por Hülsewig et al. (2009), no qual a taxa de juros para empréstimos cobrada pelos bancos influencia diretamente o custo das firmas, e a reação dessa taxa de juros a um choque de política monetária pode não ser imediata 
(pass-through limitado). Como novidade, o modelo incorpora o crédito direcionado ${ }^{1}$ como modalidade de empréstimo praticada por parte dos bancos.

Os resultados encontrados mostram que o canal de custo pode ser um importante meio de transmissão da política monetária no Brasil, explicando o price-puzzle da política monetária, e que pass-through da taxa de juros não é limitado. Além disso, os resultados indicam que quanto maior participação do crédito direcionado, menor é a capacidade de a política monetária modificar as condições do mercado de crédito.

O canal de custo da política monetária tem sido incorporado em modelos teóricos recentes. Christiano et al. (2005) apresentam um modelo DSGE Novo-Keynesiano que incorpora a hipótese de crédito para capital de giro. As firmas necessitam pagar pelos fatores de produção antes de receber as receitas de suas vendas. Como resultado, o custo marginal dessas firmas depende positivamente da taxa de juros. Além disso, uma política monetária contracionista promove uma pressão para elevação dos preços. Ravenna e Walsh (2006) introduzem outros choques econômicos (produtividade, preferências e gastos do governo) no modelo, e encontram implicações importantes em termos de condução da política monetária: o trade-off entre estabilização do produto e da inflação; e, sob política monetária ótima, produto e inflação retornam gradualmente a suas taxas de estado estacionário. Rabanal (2007), por sua vez, inova ao considerar que apenas uma fração das firmas depende do crédito para capital de giro. Hülsewig et al. (2009) inserem bancos que operam em competição monopolística, e reajustam suas taxas de juros para empréstimo com alguma rigidez (somente uma fração dos bancos é capaz de reajustar a taxa de juros para empréstimo a cada período), ou seja, o ajustamento das taxas de juros para empréstimos após um choque de política monetária não é imediato. ${ }^{2}$ De Fiori e Tristani (2013) apresentam um modelo que considera assimetria de informação (com custos de verificação dos estados a la Townsend) e risco de falência, e, por causa disso, a taxa de juros para empréstimos incorpora um spread sobre a taxa de depósito. No modelo, a taxa de inflação aumenta tanto com o spread, como com a taxa de depósito.

1 O crédito direcionado assegura fundos regulados por lei para serem destinados a segmentos ou propósitos específicos.

2 No modelo de Hülsewig et al. (2009), a estrutura do mercado de crédito desempenha papel relevante. A operacionalidade do canal de custo depende da capacidade dos bancos em reagir a choques de política monetária. Se a proporção de bancos que são capazes de reajustar suas taxas é pequena, então o efeito da política monetária através da taxa de juros para empréstimos será reduzido, e o canal de custo não será relevante. 
Segundo Hülsewig et al. (2009), há um número considerável de estudos que concluem empiricamente pela relevância do canal de custo nas economias desenvolvidas, por exemplo, os autores citam Barth e Ramey (2002), Dedola e Lippi (2005), Fabiani et al. (2006), Christiano et al. (2005), Ravenna e Walsh (2006), Chowdhury et al. (2006) e Tillmann (2008). Hülsewig et al. (2009), em um estudo para a zona do Euro, também encontram evidências de que esse canal de transmissão é importante para explicar o comportamento inercial da inflação provocado após um choque de política monetária, mas esse efeito é mitigado devido ao ajuste lento das taxas de juros para empréstimo.

Por outro lado, poucos estudos analisam o canal de custo da política monetária para países em desenvolvimento. Agénor e Montiel (2008) argumentam que o canal de custo pode ser relevante nessas economias porque os mercados de ações são fracos e o sistema bancário é fonte significativa de recursos para as operações financeiras das firmas, incluindo a aquisição de ativos de capital fixo.

O estudo sobre a relevância do canal de custo parece ser crucial para aprimorar o entendimento acerca dos efeitos da política monetária no Brasil por uma série de razões. Primeiro, as firmas brasileiras recorrem significativamente ao crédito para capital de giro. De acordo com dados do Banco Central, a participação dessa modalidade de crédito no saldo total destinado a pessoas jurídicas foi de aproximadamente $25 \%$ entre março de 2007 e dezembro de 2015.

Outra motivação para a análise do canal de custo se deve ao percentual relevante de despesas financeiras apresentado pelas empresas no país. De acordo com dados da Pesquisa Industrial Anual (IBGE), os custos com variações monetárias passivas, despesas financeiras, e resultados negativos de participações societárias e em cota de participação representaram em torno de 12\% do custo total das firmas industriais brasileiras entre 2007 e 2014. Apenas como comparação, as despesas com trabalho representaram $14 \%$ do custo total no mesmo período. Então, é provável que mudanças no montante das despesas financeiras influenciem decisões sobre preços e produção.

Há, ainda, evidências do price-puzzle da política monetária em estimações de modelos VAR para a economia brasileira, por exemplo, Rabanal e Schwartz (2001), Arquete e Jayme-Jr. (2003), Sales e Tannuri-Pianto 
(2005) e Guimarães e Monteiro (2014). É interessante destacar que, mesmo nos estudos nos quais o price-puzzle não é observado, o efeito da política monetária sobre a inflação é reduzido, defasado e temporário, como evidenciado por Fernandes e Toro (2005) e Céspedes et al. (2008).

Algumas mudanças da economia brasileira também justificam a análise do canal de custo. A condução da política monetária foi alterada recentemente, ${ }^{3}$ de modo que há pouco entendimento sobre os seus mecanismos de transmissão no Brasil. Além disso, Minella e Souza-Sobrinho (2009) argumentam que a importância relativa dos canais de transmissão da política monetária pode ter sofrido alterações, entre outras razões, por causa da expansão do mercado de crédito e o desenvolvimento do mercado financeiro.

Poucos estudos analisaram a operacionalidade do canal de custo na economia brasileira, incluindo Martins (2011), Malikane (2012), Kawamoto e Oreiro (2011) e Santos (2011). Há diferenças significativas entre eles em termos do modelo teórico, estratégia empírica e resultados - somente Martins (2011) e Kawamoto e Oreiro (2011) encontram evidências para o canal de custo. Apesar das diferenças, todos esses estudos negligenciaram o comportamento dos bancos e capacidade da taxa de juros, instrumento da política, modificar as condições de crédito enfrentadas pelas firmas.

A participação do crédito direcionado é significativa no Brasil. De acordo com o Banco Central do Brasil, essa modalidade representou 49\% do total das operações de crédito em 2015. Além disso, as operações de crédito direcionado no país apresentam características peculiares que influenciam a capacidade de a política monetária modificar as condições de crédito da economia. É possível destacar três dessas características: (i) as taxas de juros do crédito direcionado são mais baixas e mais estáveis do que as taxas das demais modalidades de crédito; (ii) o crédito direcionado é composto por fundos públicos e privados; e (iii) as operações de crédito direcionado têm sido realizadas, principalmente, por grandes bancos públicos.

Então, no modelo, admite-se que uma fração - constante e determinada exogenamente - dos empréstimos é realizada através de operações de crédito direcionado, e a taxa de juros dessas operações é também constante e determinada exogenamente ao modelo.

3 O regime de meta monetária foi substituído pelo regime de metas de inflação somente em 1999. Desde então, a taxa Selic (a taxa de juros interbancária) é o principal instrumento da política monetária (Sales e Tannuri-Pianto 2007). 
É importante mencionar que poucos estudos, a exemplo de Santin (2013) e Sato (2013), tentaram elucidar a relação entre a política monetária e o crédito direcionado. Nesse sentido, o presente estudo apresenta uma contribuição aos formuladores de política econômica, uma vez que desenvolve e estima um modelo para a economia brasileira que incorpora a proporção do crédito direcionado como determinante da influência da política monetária sobre as condições de crédito.

O modelo DSGE foi estimado por meio do método da Distância Mínima. No primeiro passo dessa abordagem, estima-se um modelo VAR para gerar funções impulso-resposta empíricas a um choque de política monetária. Em seguida, os parâmetros do modelo são obtidos aproximando, o máximo possível, as funções impulso-resposta teóricas e empíricas. Considerando o modelo estimado, analisa-se a relevância do canal de custo. Além disso, buscam-se evidências de pass-through limitado da taxa de juros e da influência do crédito direcionado sobre os efeitos da política monetária.

\section{O Modelo}

Nesta seção, descreve-se o modelo DSGE Novo-Keynesiano utilizado na análise. O modelo segue a linha de Hülsewig et al. (2009), Rabanal (2007), Ravenna e Walsh (2006) e Christiano et al. (2005), e admite que algumas firmas necessitam de recursos para financiar a produção antes de obter receita com a venda de seus produtos. A contribuição deste trabalho é a diferenciação entre as modalidades de crédito, livre e direcionado, que são concedidos pelos bancos. Além de firmas e bancos, o modelo também é composto pelas famílias, cuja poupança é utilizada pelos bancos para efetuar os empréstimos. As principais equações são detalhadas a seguir.

\subsection{Produtores de Bens Finais}

Produtores de bens finais operam em competição perfeita. A função de produção do produto agregado é dada por: 


$$
Y_{t}=\left[\int Y_{t}^{\frac{\epsilon-1}{\epsilon}}(i) d i\right]^{\frac{\epsilon}{\epsilon-1}}
$$

onde $Y_{t}$ é o produto final, $Y_{t}(i)$ é o produto intermediário indexado por $i \in[0,1]$, e $\epsilon$ é a elasticidade de substituição entre diferentes tipos de produtos.

A maximização do lucro implica na seguinte demanda por bens intermediários:

$$
Y_{t}(i)=\left(\frac{P_{t}(i)}{P_{t}}\right)^{-\epsilon} Y_{t} \text {, para todo } i \in[0,1],
$$

onde $P_{t}=\left[\int P_{t}^{1-\epsilon}(i) d i\right]^{\frac{1}{1-\epsilon}}$ é o preço do produto final e $P_{t}(i)$ é o preço do produto intermediário $i$.

\subsection{Produtores de Bens Intermediários}

Firmas indexadas por $i \in[0,1]$ operam em competição monopolística. Cada firma $i$ tem acesso a tecnologia:

$$
Y_{t}(i)=\widetilde{K}_{t}^{\alpha}(i) N_{t}^{1-\alpha}(i)
$$

onde $\widetilde{K}_{t}(i)$ é a efetiva utilização do estoque de capital, dada por $\widetilde{K}_{t}(i)=u_{t} K_{t}(i)$, sendo $u_{t}$ a taxa de utilização do capital, $N_{t}(i)$ é o trabalho, e $\alpha$ é a participação do capital no produto.

O lucro nominal da firma $i$ é dado por:

$$
\Pi_{t}^{f i r m}(i)=P_{t}(i) Y_{t}(i)-Q_{t}^{f i r m}(i)
$$

onde $Q_{t}^{\text {firm }}(i)$ é o custo nominal de produção. A firma aluga o capital em um mercado de competição perfeita e escolhe o volume de emprego. Para a massa de firmas $i \in[0, v]$, as quais necessitam de empréstimos $L_{t}(i)$ dos bancos para pagar os salários, $W_{t} N_{t}(i)$, o custo de produção nominal é dado por: $\mathrm{Q}_{t}^{\text {firm }}(i)=R_{t}^{L} W_{t} N_{t}(i)+R_{t}^{K} \widetilde{K}_{t}(i)$. O pagamento da dívida pelas firmas é feito no fim de cada período. 
Firmas $i \in[0, v]$ possuem um portfólio de empréstimos, que é diversificado em termos dos tipos de empréstimos ofertados pelos bancos que são agregados da seguinte forma:

$$
L_{t}(i)=\left[\int L_{t}^{\frac{\zeta-1}{\zeta}}(i, k) d k\right]^{\frac{\zeta}{\zeta-1}}
$$

onde $L_{t}(i)$ é a demanda de empréstimos pela firma $i$, que é igual à folha de pagamentos $W_{t} N_{t}(i)$, e $\zeta>1$ é a elasticidade de substituição entre os $k$ diferentes tipos de empréstimos. Cada firma obtém a composição ótima dos diferentes empréstimos ao escolher sua agenda de empréstimos. Agregando para todas as firmas, a demanda por empréstimos do tipo $k$ é dada por:

$$
L_{t}(k)=\left(\frac{R_{t}^{L}(k)}{R_{t}^{L}}\right)^{-\zeta} L_{t}
$$

$L_{t}(k)=\int L_{i t}(k) d i$ é a demanda por empréstimos do tipo $\mathrm{k}, L_{t}=\int L_{t}(i) d i$ é o volume agregado de empréstimos, $R_{t}^{L}=\left[\int R_{t}^{L}(k)^{1-\zeta} d k\right]^{\frac{1}{1-\zeta}}$ é a taxa de juros bruta agregada para empréstimos, e $R_{t}^{L}(k)$ é a taxa bruta para empréstimos do tipo $k$.

As firmas possuem algum poder de mercado sobre o preço do seu produto. Elas maximizam o lucro esperado por meio de um fator de desconto estocástico $\Lambda_{t, t+1}$ que é igual a taxa marginal de substituição intertemporal do consumidor representativo. Os lucros são distribuídos aos consumidores até o fim do período. Por hipótese, as firmas decidem antes da realização de qualquer distúrbio no tempo $t$. Isso significa que, por exemplo, um choque de política monetária não tem efeito imediato nos preços.

Firmas enfrentam fricções de preço como em Calvo (1983), isso implica uma determinação de preços rígida. O nível de preços $P_{t}$ é determinado em cada período como a média ponderada da fração de firmas $1-\theta_{p}$ que redefine os preços e a fração $\theta_{p}$ que deixa os preços inalterados:

$$
P_{t}=\left[\left(1-\theta_{p}\right)\left(P_{t}^{*}\right)^{1-\epsilon}+\left(\theta_{p}\right)\left(P_{t-1}\right)^{1-\epsilon}\right]^{\frac{1}{1-\epsilon}}
$$

onde $P_{t}$ é o preço redefinido. As firmas que redefinem o preço são divididas entre: as firmas que resolvem o problema de otimização mais uma vez 
para determinar os novos preços (fração $1-\omega_{p}$ ), e as firmas que aplicam uma regra de indexação à inflação passada (fração $\left.\omega_{p}\right){ }^{4}$

A maximização do lucro pelas firmas que podem alterar os preços leva a seguinte condição de primeira ordem:

$$
E_{t-1} \sum_{l=0} \theta^{l} \Lambda_{t, t+l} \mathrm{Y}_{t+l}(i)\left[P_{t}^{f}(i)-\frac{\epsilon}{\epsilon-1} P_{t+l}^{f} \varphi_{t+l}(i)\right]=0
$$

onde $P_{t}^{f}(i)$ é o preço ótimo, $E_{t-1}$ é o operador de esperança condicional ao conjunto de informações disponível em $t-1$, e $\varphi_{t}(i)$ é o custo marginal real dado por:

$$
\varphi_{t}(i)=\left\{\begin{array}{l}
\frac{1}{\Phi}\left(\frac{R_{t}^{K}}{P_{t}}\right)^{\alpha}\left(\frac{R_{t}^{L} W_{t}}{P_{t}}\right)^{1-\alpha}, \text { para } i \in[0, v] \\
\left.\left.\frac{1}{\Phi}\left(\frac{R_{t}^{K}}{P_{t}}\right)^{\alpha}\left(\frac{W_{t}}{P_{t}}\right)^{1-\alpha}, \text { para } i \in\right] v, 1\right]
\end{array}\right.
$$

sendo $\Phi=\alpha^{\alpha}(1-\alpha)^{1-\alpha}$. O preço ótimo está relacionado à expectativa de custo marginal, ou seja, $P_{t}^{f}(i)$ é um mark-up sobre a esperança do custo marginal real ponderado.

Por fim, a fração das firmas $\omega_{p}$ que redefinem o preço em cada período por meio de uma regra de indexação à inflação passada, fixam o preço de acordo com: $P_{t}^{b}=P_{t-1}^{*}\left(P_{t-1} / P_{t-2}\right)$. Desse modo, a evolução dos preços é dada por: $P_{t}^{*}=\left(P_{t}^{f}\right)^{1-\omega_{p}}\left(P_{t}^{b}\right)^{\omega_{p}}$. Essa estratégia de subdividir as firmas que podem mudar os preços a cada período foi primeiramente utilizada por Galí et al. (2001).

\subsection{Famílias}

Há um contínuo de famílias indexadas por $j \in[0,1]$. A família $j$ maximiza a esperança da utilidade no seu horizonte de vida:

$$
E_{t-1} \sum_{l=0}^{\infty} \beta^{l} U_{t+l}(j)
$$

4 Resumindo, existem três tipos de firmas em um determinado período: as firmas que não mudam os preços, as firmas que mudam os preços pelo processo de otimização, e as firmas que mudam os preços pela regra de indexação. 
onde $\beta \in(0,1)$ é um fator de desconto.

A utilidade da família $j$ no período $t$ é dada por:

$$
U_{t}(j)=\frac{\left(C_{t}(j)-H_{t}\right)^{1-\sigma}}{1-\sigma}-\frac{N_{t}^{1+\eta}(j)}{1+\eta}
$$

onde $C_{t}(j)$ é o gasto em consumo, $\sigma$ é o coeficiente de aversão ao risco, $N_{t}(j)$ é a oferta de trabalho e $\eta$ é a elasticidade da desutilidade marginal do trabalho. $H_{t}$ descreve hábitos externos que dependem positivamente do consumo agregado no período $t-1: H_{t}=h C_{t-1}$.

A família $j$ maximiza sua utilidade de vida esperada sujeita a seguinte restrição intertemporal:

$$
\begin{array}{r}
P_{t} C_{t}(j)+P_{t} I_{t}(j)+D_{t}(j)=W_{t}(j) N_{t}(j)+\left[R_{t}^{k} u_{t}(j)-P_{t} \psi\left(u_{t}(j)\right)\right] K_{t-1}(j)+ \\
R_{t-1}^{D} D_{t-1}(j)+\operatorname{Div}_{t}(j)
\end{array}
$$

Todas as famílias decidem sobre consumo $C_{t}(j)$ e investimento $I_{t}(j)$, possuem depósitos $D_{t}(j)$ em bancos a uma taxa $R_{t}^{D}$, renda do trabalho $W_{t}(j) N_{t}(j)$, renda do aluguel do capital $R_{t}^{k} u_{t}(j) \mathrm{K}_{\mathrm{t}-1}(\mathrm{j})$ menos os custos de ajustamento no caso de mudanças na utilização do capital $P_{t} \psi\left(u_{t}(j)\right) K_{t-1}(j)$, e obtém dividendos $\operatorname{Div}_{t}(j)$ das firmas e dos bancos. Uma vez que o capital é determinado no começo do período, a renda proveniente do aluguel depende do nível de capital instalado no fim do período anterior e da taxa de utilização do capital $u_{t}(j)$. Os custos da utilização do capital são, por hipótese, iguais a zero quando a taxa de utilização é igual a um, ou seja, $\psi(1)=0$.

A equação de acumulação do capital é dada por:

$$
K_{t}(j)=(1-\delta) K_{t-1}(j)+\left[1-S\left(\frac{I_{t}(j)}{I_{t-1}(j)}\right)\right] I_{t}(j)
$$

onde $\delta$ é a taxa de depreciação do capital. A evolução do estoque de capital considera os custos de ajustamento, introduzidos pela função $S($.$) , que é crescente e convexa. No estado estacionário, tem-se que$ $\bar{S}=\bar{S}^{\prime}=0$ e $\bar{S}^{\prime \prime}>0$.

Por hipótese, todas as famílias enfrentam a mesma condição inicial e os mercados são completos. Isso assegura um equilíbrio simétrico para todas as variáveis de controle exceto para $W_{t}(j)$, possibilitando excluir o índice $j$ 
exceto para o salário e demanda de trabalho. Além disso, as famílias sempre decidem antes de choques em qualquer período $t$. Isso significa que, por exemplo, um choque de política monetária não tem efeito imediato sobre o salário.

Maximizando a função objetivo sujeito à restrição intertemporal com respeito ao consumo e poupança, as condições de primeira ordem são obtidas:

$$
\begin{aligned}
& \lambda_{t}=\left(C_{t}-h C_{t-1}\right)^{-\sigma} \\
& \lambda_{t}=\beta E_{t-1}\left[\lambda_{t+1} \frac{R_{t}^{D} P_{t}}{R_{t+1}}\right]
\end{aligned}
$$

onde $\lambda_{t}$ é o multiplicador de Lagrange.

Por hipótese, as famílias fixam seus salários de forma rígida em intervalos aleatórios. Somente uma fração das famílias $1-\theta_{w}$ redefine seu salário nominal em cada período, enquanto as $\theta_{w}$ restantes não alteram os salários. O nível de salário nominal agregado satisfaz:

$$
W_{t}=\left[\left(1-\theta_{w}\right)\left(W_{t}^{*}\right)^{1-\phi}+\theta_{w} W_{t-1}^{1-\phi}\right]^{\frac{1}{1-\phi}}
$$

onde $W_{t}^{*}$ é o salário recém-definido. As famílias que redefinem seus salários em cada período são dividas na fração $1-\omega_{w}$ que otimiza novamente seus salários nominais e a fração $\omega_{w}$ que ajusta os salários de acordo com uma regra de indexação à inflação passada. ${ }^{5}$

As famílias otimizadoras escolhem o salário de modo a maximizar a função objetivo sujeita a restrição intertemporal e a demanda por seu tipo de trabalho dada por:

$$
N_{t}(j)=\left(\frac{W_{t}(j)}{W_{t}}\right)^{-\eta} N_{t}
$$

onde $N_{t}=\left[\int N_{t}^{\frac{\eta-1}{\eta}}(j) d j\right]^{\frac{\eta}{\eta-1}}$ é o nível agregado de trabalho, e $W_{t}=\left[\int W_{t}^{1-\eta}(j) d j\right]^{\frac{1}{1-\eta}}$ é o salário nominal agregado. A condição de primeira ordem associada ao problema de maximização é:

5 Resumindo, existem três tipos de famílias em um determinado período: as famílias que não reajustam os salários, as famílias que reajustam salários pelo processo de otimização, e as famílias que reajustam salários pela regra de indexação. 


$$
E_{t-1} \sum_{l=0}^{\infty}\left(\beta \theta_{w}\right)^{l} N_{t+l}(j)\left[\frac{\phi}{\phi-1} N_{t+l}^{\eta}(j)-\frac{W_{t}^{f}(j) \lambda_{t+l}}{P_{t+l}}\right]=0
$$

onde $W_{t}^{f}(j)$ é o salário nominal ótimo. As famílias que redefinem o salário adotando a regra de indexação, por hipótese, obedecem a: $W_{t}^{b}=W_{t-1}^{*}\left(P_{t-1} / P_{t-2}\right)$. A dinâmica dos salários recém-definidos é dada por: $W_{t}^{*}=\left(W_{t}^{f}\right)^{1-\omega_{w}}\left(W_{t}^{b}\right)^{\omega_{w}}$.

As condições de primeira ordem para o preço sombra do capital, investimento e a escolha da taxa de utilização do capital são:

$$
\begin{aligned}
& Q_{t}=E_{t-1}\left[\Lambda_{t, t+1}\left(Q_{t+1}(1-\delta)+r_{t+1}^{k} u_{t+1}-\psi\left(u_{t+1}\right)\right)\right] \\
& Q_{t}\left[1-S\left(\frac{I_{t}}{I_{t-1}}\right)\right]+E_{t-1} \Lambda_{t, t+1} Q_{t+1} S^{\prime}\left(\frac{I_{t+1}}{I_{t}}\right)\left(\frac{I_{t+1}}{I_{t}}\right)^{2}=1+Q_{t} S^{\prime}\left(\frac{I_{t}}{I_{t-1}}\right)\left(\frac{I_{t}}{I_{t-1}}\right) \\
& r_{t}^{k}=\psi^{\prime}\left(u_{t}\right)
\end{aligned}
$$

onde $Q_{t}$ é o preço sombra real do capital instalado, ou seja, o $Q$ de Tobin, $\Lambda_{t, t+1}$ é um fator de desconto estocástico dado por: $\Lambda_{t, t+1}=\beta^{l}\left(\lambda_{t+l} / \lambda_{t}\right)$, e $r_{t}^{k}$ é a taxa real de aluguel do capital.

\subsection{Bancos}

Os bancos, indexados por $k \in[0,1]$, concedem empréstimos às firmas em um ambiente de competição monopolística. Os lucros do banco $k$ são dados por:

$$
\Pi_{t}^{\text {bank }}(k)=R_{t}^{l}(k) L_{t}(k)-R_{t}^{d}(k) D_{t}(k)-R_{t}^{M} B_{t}(k)
$$

onde $L_{t}(k)$ é o volume de empréstimos, $R_{t}^{l}(k)$ é a taxa de juros para empréstimo, $D_{t}(k)$ é o nível de depósitos, $R_{t}^{d}(k)$ é a taxa de juros bruta que remunera os depósitos, $B_{t}(k)$ é a posição líquida do banco no mercado monetário e $R_{t}^{M}$ é a taxa de juros bruta da moeda, sendo essa última controlada pelo Banco Central. Os lucros são distribuídos para as famílias ao final de cada período. 
Para cada banco, a restrição de balanço é dada por:

$$
L_{t}(k)=D_{t}(k)+B_{t}(k)
$$

ou seja, o volume de empréstimos é igual à soma entre o nível de depósitos e a posição líquida no mercado interbancário. Além disso, considera-se que créditos do mercado interbancário e os depósitos são substitutos perfeitos como forma de refinanciamento dos bancos, o que implica que $R_{t}^{d}=R_{t}^{M}$.

O $k$-ésimo banco maximiza lucros sujeito à restrição de balanço e à demanda por empréstimos. Se o mercado de empréstimos fosse plenamente flexível, a taxa de juros dos empréstimos cobrada por cada banco seria um mark-up dos custos marginais nominais. Como os bancos enfrentam custos marginais idênticos, o valor escolhido para a taxa de juros dos empréstimos seria o mesmo para todos eles.

Entretanto, os bancos enfrentam rigidez ao determinar suas taxas de juros para empréstimos. Primeiro, uma fração $\tau_{2}$ dos bancos concedem crédito direcionado (DC) cuja taxa de juros é determinada de modo exógeno. O restante dos bancos (na proporção $1-\tau_{2}$ ) concede crédito livre (FC) e pode escolher a taxa de juros para empréstimos de modo a maximizar seus lucros. Sendo assim, a taxa agregada de juros para empréstimos é dada por:

$$
R_{t}^{L}=\left(R_{t}^{F C}\right)^{1-\tau_{2}}\left(R_{t}^{D C}\right)^{\tau_{2}}
$$

A maximização dos lucros por parte dos bancos que operam linhas de crédito livre implica a seguinte condição de primeira ordem:

$$
E_{t} \sum_{l=0}^{\infty} \tau^{l} \Lambda_{t, t+l} L_{t+l}(k)\left[R_{t}^{L *}(k)-\frac{\zeta}{\zeta-1} R_{t+l}^{M}\right]=0,
$$

onde $R_{t}^{L *}(k)$ é a taxa de juros para empréstimos ótimas, e $\Lambda_{t, t+l}$ é o fator de desconto estocástico. Por meio da demanda por empréstimos, e resolvendo a Equação (25) para a taxa ótima, tem-se que:

$$
R_{t}^{L *}(k)=\frac{\zeta}{\zeta-1} \frac{E_{t}\left[\sum_{l=0}^{\infty} \tau^{l} \Delta_{t, t}\left(R_{t+l}^{L}\right)^{\zeta} L_{t+l} R_{t+l}^{M}\right]}{E_{t}\left[\sum_{l=0}^{\infty} \tau^{l} \Delta_{t, t}\left(R_{t+l}^{L}\right)^{\zeta} L_{t+l}\right]}
$$


que é idêntica para todos os bancos, $R_{t}^{L *}(k)=R_{t}^{L *}$. Por hipótese, os bancos, ao contrário de firmas e famílias, re-otimizam suas taxas de juros para empréstimos a cada período posteriormente a qualquer tipo de choque.

Os bancos que concedem crédito livre também enfrentam fricções. Seguindo Calvo (1983), admite-se que somente uma fração $1-\tau_{1}$ dos bancos de crédito livre re-otimizam suas taxas de juros para empréstimos em cada período, enquanto que a fração $\tau_{1}$ restante mantém as taxas inalteradas:

$$
R_{t}^{F C}=\left[\left(1-\tau_{1}\right)\left(R_{t}^{L *}\right)^{1-\zeta}+\tau_{1}\left(R_{t-1}^{F C}\right)^{1-\zeta}\right]^{\frac{1}{1-\zeta}}
$$

\subsection{Pass-Through da Taxa de Juros}

Linearizando (24), (26) e (27) por meio de uma expansão de Taylor de primeira ordem, tem-se que:

$R_{t}^{L}=\frac{\left(1-\tau_{2}\right) \beta \tau_{1}}{1+\beta \tau_{1}^{2}} E_{t}\left(R_{t+1}^{F C}\right)+\frac{\left(1-\tau_{2}\right) \tau_{1}}{1+\beta \tau_{1}^{2}} R_{t-1}^{F C}+\frac{\left(1-\tau_{2}\right)\left(1-\beta \tau_{1}\right)\left(1-\tau_{1}\right)}{1+\beta \tau_{1}^{2}} R_{t}^{M}+\tau_{2} R_{t}^{C D}(28)$

A Equação (28) revela que a evolução da taxa de juros para empréstimos agregada depende da magnitude dos parâmetros $\tau_{1}$ e $\tau_{2}$. Se $\tau_{1}$ e $\tau_{2}$ tendem a zero, a taxa de juros para empréstimos agregada tende a igualar a taxa de juros da moeda, e o pass-through seria completo.

\subsection{Considerações Adicionais sobre as Taxas de Juros para Empréstimos}

Por hipótese, a taxa de juros do crédito direcionado $\left(R_{t}^{C D}\right)$ é constante ao longo do tempo:

$$
R_{t}^{C D}=\bar{R}_{t}^{C D}
$$

Além disso, considerando que não há informação o suficiente sobre a taxa de juros agregada para a economia brasileira, optou-se por substituir $R_{t}^{L}$ na Equação (28), para determinar a equação referente à dinâmica da taxa de juros do crédito livre: 
$R_{t}^{F C}=\frac{\beta \tau_{1}}{1+\beta \tau_{1}^{2}} E_{t}\left(R_{t+1}^{F C}\right)+\frac{\tau_{1}}{1+\beta \tau_{1}^{2}} R_{t-1}^{F C}+\frac{\left(1-\beta \tau_{1}\right)\left(1-\tau_{1}\right)}{1+\beta \tau_{1}^{2}} R_{t}^{M}$

$\mathrm{Na}$ prática, a taxa de juros do crédito direcionado, apesar de relativamente estável, não é fixa. ${ }^{6}$ Além disso, observa-se alguma correlação dessa taxa Selic, ainda que em escala muito inferior a do crédito livre. ${ }^{7}$ Portanto, é possível que o modelo superestime um pouco o impacto do crédito direcionado.

\subsection{Modelo Linearizado}

As equações apresentadas a seguir consistem na aproximação log-linear das equações relevantes do modelo ao redor do estado estacionário com inflação igual a zero. A representação $\hat{X}_{t}$ denota o desvio log-linear do valor de estado estacionário da variável $X, \widehat{X}_{t}=\ln \left(X_{t}\right)-\ln \left(\bar{X}_{t}\right)$, onde $\bar{X}_{t}$ é o valor de estado estacionário.

A dinâmica do produto real $\widehat{Y}_{t}$ é descrita pelo equilíbrio no mercado de bens:

$$
\hat{Y}_{t}=\gamma_{c} \hat{C}_{t}+\left(1-\gamma_{c}\right) \hat{I}_{t}+\alpha\left(1-\frac{1}{\epsilon}\right) \hat{u}_{t}
$$

onde: $\gamma_{c}=1-\left[\alpha \delta\left(1-\frac{1}{\epsilon}\right) /\left(\frac{1}{\beta}-1+\delta\right)\right]$.

As equações do consumo e investimento são dadas por:

$$
\begin{aligned}
& \hat{C}_{t}=\frac{1}{1+h} E_{t-1} \hat{C}_{t+1}+\frac{h}{1+h} \hat{C}_{t-1}-\frac{1-h}{(1+h) \sigma} E_{t-1}\left(\hat{R}_{t}^{M}-\pi_{t+1}\right) \\
& \hat{I}_{t}=\frac{\beta}{1+\beta} E_{t-1} \hat{I}_{t+1}+\frac{1}{1+\beta} \hat{I}_{t-1}+\frac{1}{\bar{S} \prime \prime(1+\beta)} E_{t-1} \hat{Q}_{t}
\end{aligned}
$$

6 No Brasil, as operações de crédito direcionado para pessoas jurídicas são, em grande medida, operadas pelo BNDES. De acordo com dados do Banco Central do Brasil (BCB), entre 2007 e 2013, em média $74 \%$ do saldo de crédito direcionado à pessoa jurídica foi disponibilizado pelo BNDES. As taxas de juros dessas operações têm como base a TJLP (Lei n ${ }^{\circ}$ 9.365, de 16 de dezembro de 1996), acrescida da taxa de remuneração do banco, a taxa de risco de crédito, e a remuneração da instituição financeira (no caso de operações indiretas). Os valores destes componentes adicionais variam de acordo com a linha de crédito. A TJLP, por sua vez, é determinada pela meta de inflação adotada e prêmio pelo risco, o que o explica seu comportamento bastante estável.

7 O BCB fornece dados para a taxa de juros média das operações de crédito livre e direcionado para pessoas jurídicas no período de 2007 a 2017. Nesse período, os coeficientes de correlação entre essas taxas de juros e a taxa Selic foram iguais, respectivamente, a 0,97 e 0,67. 
onde $\pi_{t}$ é a taxa de inflação definida como $\pi_{t}=\hat{P}_{t}-\hat{P}_{t-1}$.

As equações do preço sombra real do capital, acumulação de capital, taxa de aluguel real do capital, e taxa de utilização do capital são respectivamente:

$$
\begin{aligned}
\hat{Q}_{t}=\beta & (1-\delta) E_{t-1} \hat{Q}_{t+1}+[1-\beta(1-\delta)] E_{t-1} \hat{r}_{t+1}^{k}-E_{t-1}\left(\hat{R}_{t}^{M}-\pi_{t+1}\right) \\
\widehat{K}_{t} & =(1-\delta) \widehat{K}_{t-1}+\delta \hat{I}_{t} \\
\hat{r}_{t}^{k} & =\hat{Y}_{t}-\hat{u}_{t}-\widehat{K}_{t-1}+\hat{\varphi}_{t} \\
\hat{u}_{t} & =\psi \hat{r}_{t}^{k}
\end{aligned}
$$

onde $\psi=\Psi^{\prime}(1) / \Psi^{\prime \prime}(1)$, sendo a taxa de utilização do capital no estado estacionário igual a um.

A evolução da taxa de inflação é descrita pela seguinte curva de Phillips Novo-Keynesiana:

$$
\pi_{t}=\gamma_{f} E_{t-1} \pi_{t+1}+\gamma_{b} \pi_{t-1}+\kappa_{p} E_{t-1} \hat{\varphi}_{t}
$$

onde: $\gamma_{f}=\beta \theta_{p} /\left\{\theta_{p}+\omega_{p}\left[1-\theta_{p}(1-\beta)\right]\right\}, \gamma_{b}=\omega_{p} /\left\{\theta_{p}+\omega_{p}\left[1-\theta_{p}(1-\beta)\right]\right\}$, $\kappa_{p}=\left(1-\theta_{p}\right)\left(1-\beta \theta_{p}\right)\left(1-\omega_{p}\right) /\left\{\theta_{p}+\omega_{p}\left[1-\theta_{p}(1-\beta)\right]\right\}$. O parâmetro $\kappa_{p}$ mensura a sensibilidade da taxa de inflação em relação aos custos marginais reais $\left(\hat{\varphi}_{t}\right)$ que são:

$$
\hat{\varphi}_{t}=\alpha \hat{r}_{t}^{k}+(1-\alpha)\left(\widehat{W}_{t}-\hat{P}_{t}+v \hat{R}_{t}^{L}\right)
$$

Os custos marginais reais, e consequentemente a taxa de inflação, dependem da taxa de juros para empréstimos como enfatizado pelo canal de custo da política monetária.

A taxa de inflação dos salários $\left(\Delta \widehat{W}_{t}\right)$ é dada por:

$$
\begin{gathered}
\Delta \widehat{W}_{t}=\beta \rho_{1} E_{t-1} \Delta \widehat{W}_{t+1}+\omega_{w} \rho_{1} \Delta \widehat{W}_{t-1}-\beta \theta_{w} \rho_{2} E_{t-1} \pi_{t}+ \\
\rho_{2} \pi_{t-1}+\kappa_{w} E_{t-1}\left[\widehat{M R S}_{t}-\widehat{W}_{t}+\widehat{P}_{t}\right]
\end{gathered}
$$

onde: $\rho_{1}=\theta_{w} /\left\{\omega_{w}+\theta_{w}\left[1-\omega_{w}\left(1-\beta \theta_{w}\right)\right]\right\}, \rho_{2}=\omega_{w}\left(1-\theta_{w}\right) /\left\{\omega_{w}+\right.$ $\left.\theta_{w}\left[1-\omega_{w}\left(1-\beta \theta_{w}\right)\right]\right\}, \kappa_{w}=\left(1-\theta_{w}\right)\left(1-\beta \theta_{w}\right)\left(1-\omega_{w}\right) /\left\{\omega_{w}+\theta_{w}[1-\right.$ $\left.\left.\omega_{w}\left(1-\beta \theta_{w}\right)\right](1+\eta \phi)\right\}$. 
A expressão para taxa marginal de substituição $\left(\widehat{M R S}_{t}\right)$ é:

$$
\widehat{M R S}_{t}=\frac{\eta}{1-\alpha} \widehat{Y}_{t}-\frac{\alpha \eta}{1-\alpha}\left(\hat{u}_{t}+\widehat{K}_{t-1}\right)+\frac{\sigma}{1-h}\left(\hat{C}_{t}-h \hat{C}_{t-1}\right)
$$

A dinâmica da taxa de juros para empréstimos é dada por:

$$
\hat{R}_{t}^{L}=\beta v_{1} E_{t}\left(\hat{R}_{t}^{F C}\right)+v_{1}\left(1-\tau_{2}\right) \hat{R}_{t-1}^{F C}+v_{2} \hat{R}_{t}^{M}
$$

onde: $v_{1}=\tau_{1}\left(1-\tau_{2}\right) /\left\{1+\beta \tau_{1}^{2}\right\}, v_{2}=\left(1-\beta \tau_{1}\right)\left(1-\tau_{1}\right)\left(1-\tau_{2}\right) /\left\{1+\beta \tau_{1}^{2}\right\}$.

Considerando as Equações (29) e (30), a dinâmica da taxa de juros para o crédito livre é dada por:

$$
\hat{R}_{t}^{F C}=\beta \iota_{1} E_{t}\left(\hat{R}_{t+1}^{F C}\right)+\iota_{1} \hat{R}_{t-1}^{F C}+\iota_{2} \hat{R}_{t}^{M}
$$

onde: $\iota_{1}=\tau_{1} /\left\{1+\beta \tau_{1}^{2}\right\}, \iota_{2}=\left(1-\beta \tau_{1}\right)\left(1-\tau_{1}\right) /\left\{1+\beta \tau_{1}^{2}\right\}$.

Das Equações (42) e (43), tem-se que:

$$
\hat{R}_{t}^{L}=\left(1-\tau_{2}\right) \hat{R}_{t}^{F C}
$$

O modelo é finalizado pela função de reação do banco central descrita pela seguinte regra log-linearizada para a taxa de juros:

$$
\hat{R}_{t}^{M}=\mu_{1} \hat{R}_{t-1}^{M}-\mu_{2} \hat{R}_{t-2}^{M}+\left(1-\mu_{1}-\mu_{2}\right)\left[\frac{\mu_{\pi}}{4} \sum_{s=0}^{3} \pi_{t-s}+\frac{\mu_{\widehat{Y}}}{2} E_{t}\left(\hat{Y}_{t+1}+\hat{Y}_{t+2}\right)\right]+
$$

Os parâmetros $\mu_{1}$ e $\mu_{2}$ capturam o grau de suavização da taxa de juros, $\mu_{\pi}$ é o coeficiente de reação relacionado às taxas de inflação presente e passada, $\mu_{\pi}$ é o coeficiente de reação relacionado à expectativa para o gap do produto, $\mu_{\Delta \widehat{Y}}$ é o coeficiente de mudanças no gap do produto, e $z_{t}^{M}$ é o choque de política monetária.

\section{Metodologia Empírica}

A versão log-linear do modelo DSGE foi estimada com o objetivo de analisar a relevância do canal de custo da política monetária, o pass-through da taxa de juros, e o papel do crédito direcionado na transmissão da 
política monetária. Para tanto, aplicou-se a abordagem da Distância Mínima como em Christiano et al. (2005), Carrillo et al. (2007), Henzel et al. (2009) e Hülsewig et al. (2009). Esse método de estimação consiste em duas etapas. Primeiro, um modelo VAR é especificado para gerar funções impulso-resposta empíricas relacionadas, nesse caso, a choques de política monetária. Em seguida, os parâmetros do modelo são estimados de modo a aproximar, o máximo possível, as funções impulso-resposta teóricas e empíricas.

\subsection{Choque de Política Monetária e Modelo VAR}

Como em Christiano et al. (2005), define-se a política monetária como:

$$
R_{t}=f\left(\Phi_{t}\right)+\epsilon_{t}
$$

onde $R_{t}$ é a taxa de juros de curto prazo da moeda (o instrumento da política), $f$ é uma função linear, $\Phi_{t}$ é um conjunto de informações relevantes e $\epsilon_{t}$ é o choque de política monetária. Por hipótese, o banco central permite variações da oferta de moeda que assegura a Equação (46) em qualquer circunstância, e $\epsilon_{t}$ é ortogonal aos elementos em $\Phi_{t}$.

Considerando essa caracterização da política monetária, o modelo VAR estimado para a economia brasileira possui a seguinte especificação:

$$
Z_{t}=A(L) Z_{t-l}+\varepsilon_{t}
$$

onde $Z_{t}$ é o vetor de variáveis endógenas, $A(L)$ é a matriz dos parâmetros, e $\varepsilon_{t}$ é o vetor de resíduos que, por hipótese, é ruído branco. O vetor $Z_{t}$ é composto por:

$$
Z_{t}=\left(G D P_{t}, I N F_{t}, W I N F_{t}, R M_{t}, R L_{t}\right)
$$

onde $G D P_{t}$ é o PIB real, $I N F_{t}$ é a taxa de inflação, $W I N F_{t}$ é a taxa de inflação dos salários nominais, $R M_{t}$ is a taxa de juros da moeda, e $R L_{t}$ é a taxa de juros dos empréstimos.

As respostas das variáveis de $Z_{t}$ a um choque de política monetária são estimadas por meio do modelo VAR. A identificação do choque é feita através da decomposição de Choleski (decomposição recursiva). 
O ordenamento das variáveis implica que o produto real, a taxa de inflação, e a taxa de inflação dos salários nominais são afetadas por um choque de política monetária com defasagem, enquanto que a taxa de juros da política monetária e a taxa de juros dos empréstimos são afetadas contemporaneamente. Esse esquema de identificação é passível de discussão, mas deixa a análise internamente consistente uma vez que as hipóteses são as mesmas do modelo teórico.

\subsection{Método da Distância Mínima}

Alguns parâmetros do modelo foram estimados buscando minimizar a distância entre as funções impulso-resposta teóricas e empíricas. O conjunto de parâmetros estimados $(\varrho)$ é:

$$
\varrho=\left(h, \theta_{p}, \omega_{p}, \theta_{w}, \omega_{w}, \mu_{1}, \mu_{\hat{Y}}, \mu_{\pi}, \tau, \bar{S}^{\prime \prime}, \mu_{2}, \mu_{\Delta \hat{Y}}, v\right)
$$

O estimador minimiza a seguinte função distância (Christiano et al., 2005):

$$
J=(\widehat{\Gamma}-\Gamma(\varrho))^{\prime} V^{-1}(\widehat{\Gamma}-\Gamma(\varrho))
$$

onde $\widehat{\Gamma}$ são as funções impulso-resposta empíricas, $\Gamma(\varrho)$ são as funções impulso-resposta teóricas, e $V$ é a matriz de pesos, cujos itens da diagonal são as variâncias amostrais de $\widehat{\Gamma}$. A matriz de pesos assegura maior prioridade aos pontos com os menores valores de desvio-padrão ${ }^{8}$ (Henzel et al. 2009).

Os demais parâmetros são calibrados com base em evidências empíricas obtidas a partir de dados da economia brasileira e de evidências de estudos anteriores. A calibração de um subconjunto de parâmetros é uma prática usual em estimações de modelos DSGE, pois alguns parâmetros não são identificados através de estratégias de estimação irrestritas. A decisão sobre quais parâmetros serão estimados, por outro lado, raramente é discutida, e costuma variar entre os estudos. Nesse sentido, optou-se por seguir as escolhas de Hülsewig et al. (2009).

8 Seguindo Hülsewig et al. (2009), emprega-se a rotina fmincon do MATLAB para resolver esse problema de minimização. Para o uso da rotina, é necessário definir as condições iniciais dos parâmetros, $\varrho_{0}=(0,50,50,50,50,51,51,51,10,52,50,51,50,5)$ que foram obtidos como a média dos valores dos limites inferior, $\varrho_{-}=(0,00,00,00,00,01,00,01,00,00,00,00,00,0)$, e superior, $\varrho_{+}=(1,01,01,01,01,02,03,02,01,05,01,03,01,0)$, que os parâmetros poderiam apresentar. Como análise de robustez, o procedimento de estimação foi repetido 500 vezes a partir de diferentes condições iniciais. Os resultados desse exercício estão no Apêndice B. 
De acordo com Smets e Wouters (2003), a estimação de modelos DSGE por métodos que procuram aproximar o máximo possível momentos teóricos e empíricos, como o descrito anteriormente, possuem duas vantagens: destacam as características dos dados para as quais o modelo é mais relevante; são mais robustos do que os métodos de máxima verossimilhança.

É importante destacar que os métodos de máxima verossimilhança podem incorrer no problema denominado de singularidade estocástica. Mais especificamente, as soluções de modelos DSGE determinam identidades que envolvem as variáveis, e, se essas identidades não são satisfeitas pelos dados, nenhuma tentativa de ajustamento do modelo por métodos de máxima verossimilhança será bem-sucedida (Tovar 2009). A singularidade estocástica tende a ocorrer quando o número de choques teóricos é menor do que o número de variáveis endógenas (Boivin e Giannoni 2006). No modelo apresentado na seção anterior, há apenas um choque econômico. Portanto, a abordagem da distância mínima é mais apropriada para estimar os parâmetros.

\subsection{Dados}

Os dados utilizados, de periodicidade trimestral (2000:3 - 2013:4)13, são referentes ao logaritmo natural do índice encadeado do PIB (IBGE), da inflação medida pela variação anualizada do deflator do PIB (IBGE), da inflação dos salários medida pela variação anualizada do rendimento médio nominal habitual do trabalho principal (PME/IBGE), variação anualizada do índice de preço de commodities (FMI), taxa de juros interbancária Over-Selic (BCB), e a média das taxas de juros das operações de crédito livre para pessoas jurídicas (BCB).

\section{Resultados}

\subsection{Estimação do Modelo Teórico}

A Figura 1 mostra os gráficos das funções impulso-resposta de cada variável do modelo VAR para um choque de política monetária dado por um 
aumento de aproximadamente 1,0 p.p. na taxa Selic. ${ }^{9}$ O horizonte de tempo para as resposta é igual a 20 períodos em todos os gráficos. O PIB real reduz gradualmente até o segundo período posterior ao choque, quando alcança variação negativa de $0,4 \%$, depois o choque tende a dissipar lentamente. A taxa de inflação aumenta no primeiro período após o choque, e reduz gradualmente até o sétimo período, tendendo a retornar à linha base depois disso. O primeiro movimento da taxa de inflação reflete o pricepuzzle. ${ }^{10} \mathrm{~A}$ inflação do salário nominal também apresenta variação positiva no primeiro trimestre posterior ao choque, mas, nesse caso, o intervalo de confiança também inclui valores negativos. Por fim, a taxa de juros dos empréstimos se comporta de modo muito semelhante à Selic.
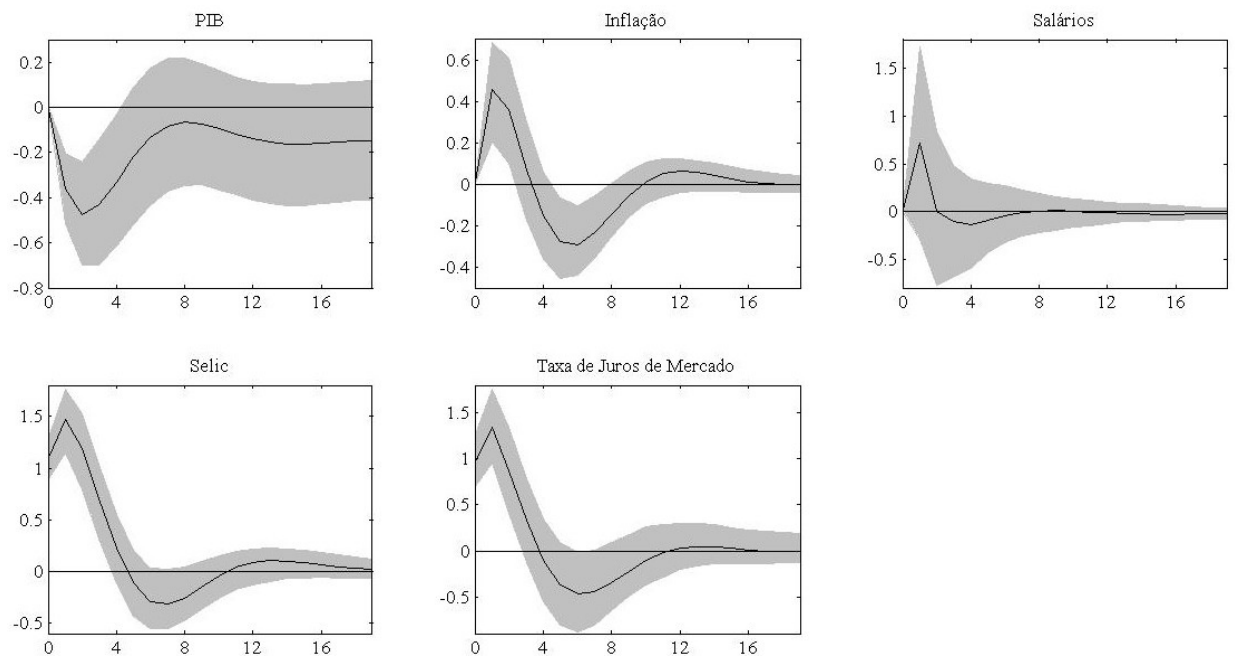

Figura 1 - Choque de Política Monetária

Nota: O eixo horizontal é medido em trimestres. As linhas cheias representam as impulso-respostas calculadas como média obtida de um procedimento bootstrap com 2000 replicações. As áreas sombreadas demarcam os intervalos de $95 \%$ de confiança.

9 O modelo VAR foi estimado considerando duas defasagens e três variáveis dummies. A primeira dummy assume o valor 1 em 2003:1 e 2003:2, período de transição entre os governos dos presidentes Fernando Henrique Cardoso e Luís Inácio Lula da Silva, assume 0 nos outros trimestres. A segunda dummy assume o valor 1 em 2002:2 e 0 nos outros trimestres, para lidar com um outlier na série da inflação dos salários nominais que é resultado de uma mudança metodológica da pesquisa. Finalmente, a terceira dummy assume 1 apenas em 2008:4 e 2009:1 que é o período de maior impacto da última crise financeira no Brasil. Os resultados dos testes de especificação para o modelo VAR estimado estão no Apêndice A.

${ }^{10}$ Para lidar com o price-puzzle, estimou-se o modelo VAR introduzindo-se explicitamente a inflação do preço de commodities $\left(C P I_{t}\right)$, com base nos dados do Banco Central do Brasil. No entanto, os resultados em termos das respostas das variáveis foram basicamente os mesmos. 
Importante destacar que as dinâmicas das variáveis PIB real, inflação e taxa de juros após um choque de política monetária são bastante similares àquelas apresentadas por Hülsewig et al. (2009), ao estudar a zona do Euro. Há uma diferença no comportamento da inflação dos salários nominais que, no caso do referido estudo, não cresce imediatamente após o choque de política.

Alguns parâmetros do modelo foram calibrados com base em evidências empíricas compatíveis com as informações sobre a economia brasileira. Esses valores também foram utilizados por outros estudos como, por exemplo, Christiano et al. (2005), Smets e Wouters (2003), Smets e Wouters (2007), Rabanal e Rubio-Ramírez (2007), Hülsewig et al. (2009), Vereda e Cavalcanti (2010), Cavalcanti e Vereda (2011), Carvalho e Valli (2011) e Vasconcelos e Divino (2012), sendo os quatro últimos específicos para a economia brasileira. A Tabela 1 mostra os valores utilizados. $O$ fator de desconto, $\beta$, foi igualado a 0,99 , o que implica uma taxa de juros real de estado estacionário igual a $4 \%$ ao ano. As elasticidades da função utilidade, $\sigma$ e $\eta$, foram consideradas iguais a 2. A participação do capital no produto, $\alpha$, foi fixada em 0,3 . A taxa de depreciação, $\delta$, foi igual a 0,025 , compatível com uma taxa anual de depreciação de $10 \%$. Os parâmetros $\phi$ e $\epsilon$ foram iguais a 11, implicando mark-ups de preços e salários iguais a $10 \%$ no estado estacionário. A elasticidade da utilização do capital $\psi$ foi fixada em 100 . Por fim, $\tau_{2}$ foi considerado igual 0,4 , implicando que a proporção de bancos que operam o crédito direcionado é igual a $40 \%$, valor aproximadamente igual à proporção média do volume dessa modalidade de crédito no Brasil ao longo de 2013 (último ano da amostra). ${ }^{11}$

Tabela 1 - Parâmetros Calibrados

\begin{tabular}{clr}
\hline Parâmetro & Descrição & Valor \\
\hline$\beta$ & Fator de Desconto & 0,99 \\
$\sigma$ & Grau de Aversão ao Risco & 2,00 \\
$\eta$ & Elasticidade da Oferta de Trabalho & 2,00 \\
$\varphi$ & Poder de Monopólio dos Consumidores & 11,00 \\
$\delta$ & Taxa de Depreciação & 0,0025 \\
$\alpha$ & Participação do Capital & 0,30 \\
$\epsilon$ & Poder de Monopólio das Firmas & 1100 \\
$\psi$ & Elasticidade da Utilização de Capital & 100,00 \\
$\tau_{2}$ & Proporção de Bancos que Operam Crédito Direcionado & 0,40 \\
\hline
\end{tabular}

${ }^{11}$ Como análise de robustez, o modelo foi estimado considerando valores diferentes dos parâmetros calibrados. Os resultados estão no Apêndice C. 
Os demais parâmetros do modelo foram estimados através da minimização entre as distâncias das funções impulso-resposta teóricas e empíricas. A Figura 2 mostra o resultado desse procedimento de aproximação. O modelo estimado parece ser capaz de replicar os dados, uma vez que as funções impulso-resposta teóricas permanecem dentro do intervalo de confiança empírico.
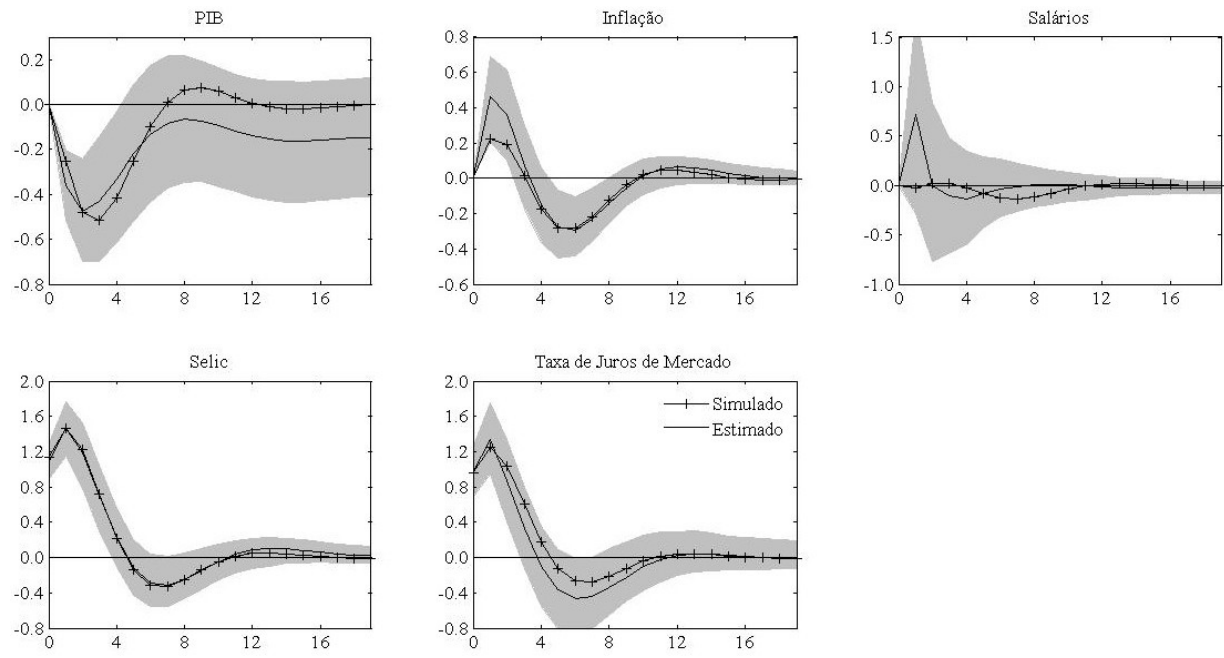

Figura 2 - Matching das Funções Impulso-Resposta

Nota: O eixo horizontal é medido em trimestres. As linhas cheias representam as impulso-respostas calculadas como média obtida de um procedimento bootstrap com 2000 replicações. As áreas sombreadas demarcam os intervalos de $95 \%$ de confiança. As linhas marcadas correspondem às funções impulso-resposta teóricas.

A Tabela 2 apresenta as estimativas obtidas para os parâmetros contidos no vetor $\varrho,{ }^{12}$ e seus respectivos valores de desvio-padrão. O grau de formação de hábitos de consumo, $h$, foi igual a 0,90 , implicando que a resposta do consumo a um choque de política monetária é fortemente guiado pelos hábitos, e que a política tem efeito direto reduzido. $\mathrm{O}$ valor usado para esse parâmetro em Vereda e Cavalcanti (2010) foi 0,825.

${ }^{12}$ Como análise de robustez, o valor da função objetivo foi calculado variando-se os valores dos parâmetros ao redor das estimativas encontradas. Os resultados estão no Apêndice B. 
Tabela 2 - Parâmetros Estimados

\begin{tabular}{clcc}
\hline Parâmetro & Descrição & Coeficiente & Desv. Pad. \\
\hline$h$ & Formação de Hábitos de Consumo & 0,90 & 0,09 \\
$\theta_{p}$ & Rigidez de Preços & 0,11 & 0,40 \\
$\omega_{p}$ & Indexação de Preços & 0,41 & 0,14 \\
$\theta_{w}$ & Rigidez dos Salários & 0,65 & 0,07 \\
$\omega_{w}$ & Indexação dos Salários & 0,53 & 0,10 \\
$\overline{S^{\prime \prime}}$ & Custos de Ajustamento de Investimento & 5,00 & 2,51 \\
$\mu_{1}$ & Regra de Taylor: suavização & 1,81 & 0,17 \\
$\mu_{2}$ & Regra de Taylor: suavização & 0,93 & 0,20 \\
$\mu_{\hat{Y}}$ & Regra de Taylor: produto & 3,00 & 0,79 \\
$\mu_{\pi}$ & Regra de Taylor: inflação & 1,00 & 0,62 \\
$\mu_{\Delta}$ & Regra de Taylor: crescimento & 0,99 & 0,30 \\
$\tau_{1}$ & Rigidez das Taxas de Juros & 0,19 & 0,11 \\
$v$ & Participação do Canal de Custo & 0,72 & 0,26 \\
\hline
\end{tabular}

Nota: o valor da função distância foi igual a 51,4l com probabilidade de 0,99. Essa probabilidade foi calculada empregando uma distribuição $\chi^{2}$ com 84 graus de liberdade. O número de graus de liberdade é igual à diferença entre o número de observações estimadas das funções impulso-resposta (97) e o número de parâmetros estimados (13). Como o valor da função distância foi menor do que o valor crítico a 1\%, as restrições impostas não podem ser rejeitadas.

A estimativa para o parâmetro referente aos custos de ajustamento do investimento, $\bar{S}^{\prime \prime}$, foi igual a 5,00 , mas o desvio-padrão revela um elevado grau de incerteza. O valor para esse parâmetro estimado por Carvalho e Valli (2011) foi de 2,35.

Os resultados também indicam um baixo grau de rigidez de preços. O valor do parâmetro $\theta_{p}$ foi 0,11 . Por outro lado, a proporção de firmas que adotam regras de indexação, $\omega_{p}$, é significante, sendo igual a 0,41 .

A rigidez dos salários é elevada. As estimativas para $\theta_{w}$ e $\omega_{w}$ foram 0,65 e 0,53 respectivamente. Esses resultados estão em linha com Vereda e Cavalcanti (2010), Cavalcanti e Vereda (2011), Carvalho e Valli (2011) e Vasconcelos e Divino (2012). 
Não foi encontrada evidência contundente de pass-through incompleto da taxa de juros, uma vez que o parâmetro $\tau_{1}$ foi igual a 0,19, ou seja, 19\% dos bancos que operam crédito livre não são capazes de reajustar suas taxas de juros. Portanto, o mercado financeiro revela um baixo grau de rigidez no Brasil.

O resultado para o parâmetro $v$ constitui-se uma evidência para a relevância do canal de custo da política monetária. O valor estimado para esse parâmetro foi 0,72 , ou seja, $72 \%$ das empresas dependem de crédito bancário para financiar sua produção, e, consequentemente, um aumento da taxa de juros promove um aumento dos custos.

Por fim, os parâmetros estimados da regra de Taylor foram os seguintes: coeficiente da inflação $\left(\mu_{\pi}\right)$ igual a 1,00 , coeficiente do gap do produto $\left(\mu_{\hat{Y}}\right)$ igual a 3,00 , coeficiente da taxa de crescimento do gap do produto $\left(\mu_{\Delta \hat{Y}}\right)$ igual a 0,99 , e o grau de suavização da taxa de juros, dado pela diferença entre os coeficientes autorregressivos $\mu_{1}$ e $\mu_{2}$, igual a 0,88 . $^{13}$

\subsection{Análise de Cenários}

Como forma de avaliar a relevância do canal de custo, igualou-se a zero a proporção de firmas que dependem do crédito para financiar a produção $v=0$, mantendo-se os demais parâmetros com os mesmos valores utilizados anteriormente. A Figura 3 mostra os efeitos dessa modificação em termos das respostas das variáveis a um choque de política monetária. Os custos marginais e a inflação não crescem no período imediatamente posterior ao choque quando $v=0$. Esse resultado é uma possível evidência de que o canal de custo desempenha um papel relevante na transmissão da política monetária, ajudando a explicar o price-puzzle observado na estimação do modelo VAR, e corrobora Martins (2011), para a economia brasileira, e a evidência empírica de outros estudos, tais como Barth e Ramey (2002), Gaiotti e Secchi (2006), Christiano et al. (2005), Ravenna e Walsh (2006), Chowdhury et al. (2006), Tillmann (2008) e Hülsewig et al.(2009). Por outro lado, a resposta do PIB não mostra uma mudança significativa, implicando, nesse caso, que a política monetária age pelo lado da demanda.

${ }^{13} \mathrm{O}$ grau de suavização é similar aos valores encontrados por Vereda e Cavalcanti (2010), Cavalcanti e Vereda (2011), Carvalho e Valli (2011) e Vasconcelos e Divino (2012). 


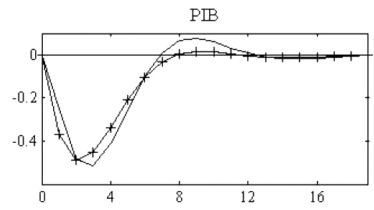

Inflação

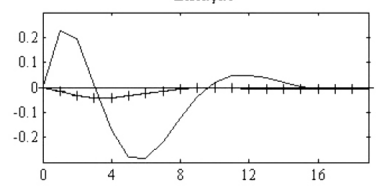

Selic

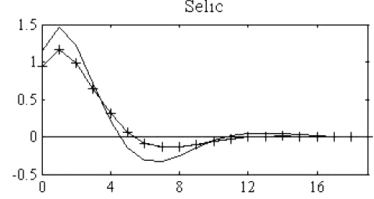

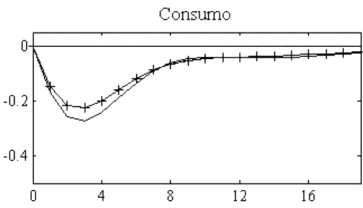

Salários

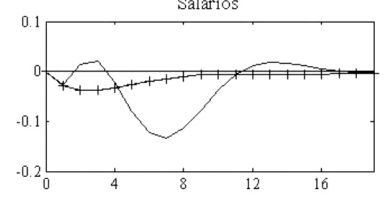

Juros de Mercado

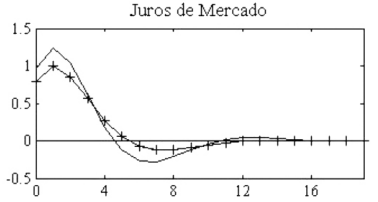

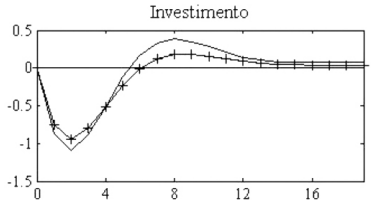
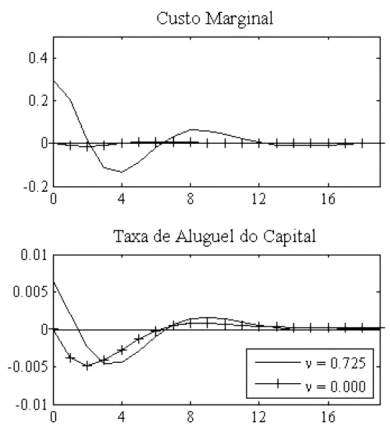

Figura 3 - Choque de Política Monetária sem o Canal de Custo

Nota: As linhas cheias são as respostas do modelo considerando $v=1$ e as linhas marcadas são as respostas do modelo considerando $v=0$.

A Figura 4 apresenta as respostas das variáveis do modelo a um choque de política monetária em um cenário de pass-through completo da taxa de juros $\left(\tau_{1}=0\right)$. A modificação do valor de $\tau_{1}$ não altera a resposta de nenhuma das variáveis de modo significativo, exceto a taxa de juros das operações de crédito que responde ao choque na mesma intensidade da Selic. Portanto, não parece existir rigidez no mercado financeiro brasileiro, ao menos em termos do crédito livre. 


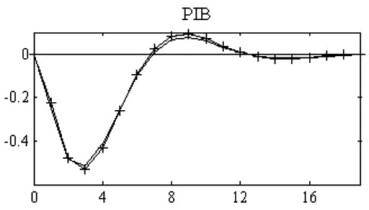

Inflação

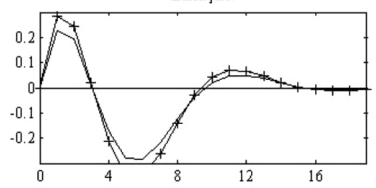

Selic

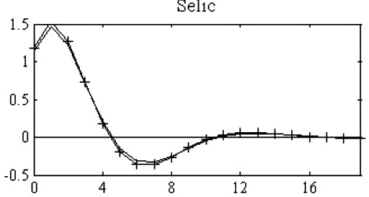

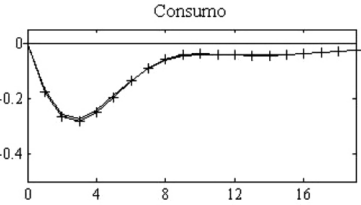

Salários
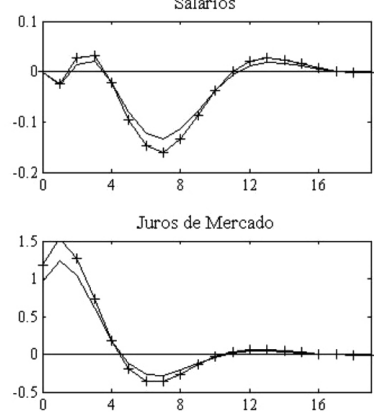

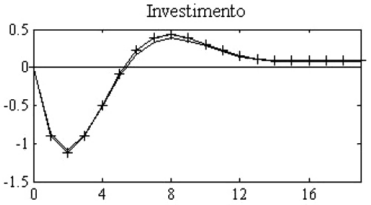

Custo Marginal

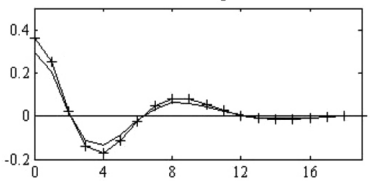

Taxa de Aluguel do Capital

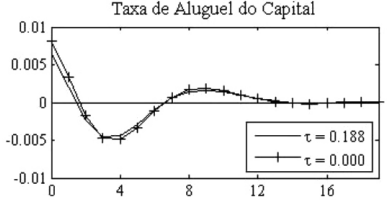

Figura 4 - Choque de Política Monetária com Pass-Through Completo da Taxa de Juros

Nota: As linhas cheias são as respostas do modelo considerando $\tau_{1}=0,36$ e as linhas marcadas são as respostas do modelo considerando $\tau_{1}=0$.

A Figura 5, por sua vez, mostra as respostas das variáveis a um choque de política monetária em um cenário no qual não há crédito direcionado $\left(\tau_{2}=0\right)$. Mantendo todos os demais parâmetros constantes, a resposta do PIB real, da inflação, da inflação dos salários, dos custos marginais e da taxa de aluguel se intensificam. Esse resultado parece indicar que quanto maior a participação do crédito direcionado, menor a influência da política monetária. A resposta do consumo praticamente não muda, indicando que a dinâmica dessa variável é determinada principalmente pela formação de hábitos.

A relação negativa entre a participação do crédito direcionado e a potência da política monetária ocorre porque as taxas de juros das operações de crédito livre se tornam mais representativas à medida que a participação do crédito direcionado se reduz, e, como não há evidência de pass-through limitado da taxa de juros, a política monetária terá maior influência sobre as condições de crédito. Por exemplo, uma política monetária contracionista, dada por um aumento na taxa de juros, promove um crescimento mais significativo da taxa de juros das operações de crédito. Então, o efeito da política monetária nos custos financeiros das firmas também será intensificado, aumentando, consequentemente, o price-puzzle. 
Esse resultado corrobora Sato (2013) e Santin (2013). De acordo com Sato (2013), a política monetária promove mudanças significativas na oferta de crédito no Brasil, mas o impacto das mudanças nas condições de crédito sobre a produção é reduzido. Santin (2013), por sua vez, afirma que a força da política monetária diminui com a adoção de políticas de crédito, especialmente, sua capacidade de controlar a inflação.
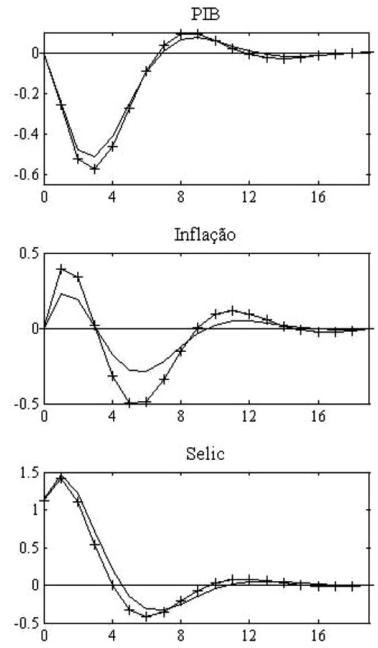

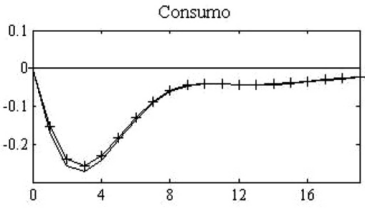

Salários
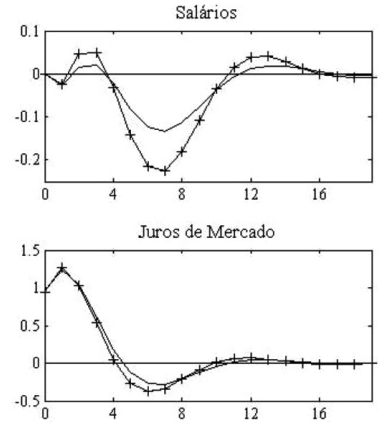
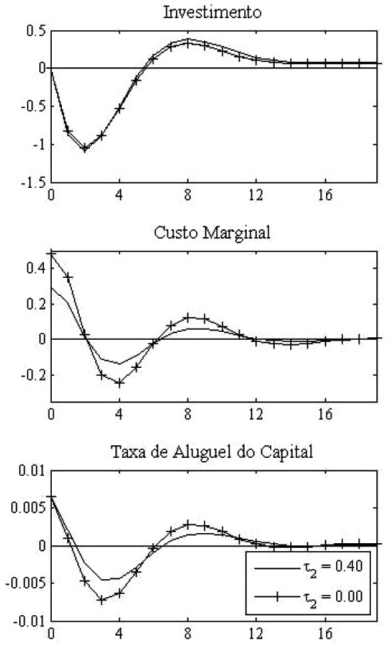

Figura 5 - Choque de Política Monetária sem Crédito Direcionado

Nota: As linhas cheias são as respostas do modelo considerando $\tau_{2}=0,40$ e as linhas marcadas são as respostas do modelo considerando $\tau_{2}=0$.

\section{Conclusões}

O presente artigo buscou analisar o canal de custo da política monetária no Brasil, destacando o papel desempenhado pelos bancos. Para tanto, desenvolveu-se um modelo DSGE Novo-Keynesiano no qual: a taxa de juros das operações de crédito influencia diretamente o custo das empresas; o pass-through da taxa de juros poderia ser limitado; e parte dos empréstimos é feita por meio do crédito direcionado.

O modelo foi estimado para a economia brasileira por meio da abordagem da distância mínima. Os resultados indicaram que: existe um elevado nível de rigidez de preços; não há evidência de pass-through incompleto da taxa 
de juros; o canal de custo da política monetária é relevante para explicar a dinâmica da inflação (e o price-puzzle) após um choque de política monetária; por fim, a participação do crédito direcionado reduz a capacidade da política monetária em modificar as condições de crédito.

\section{Referências}

Agénor, Pierre-Richard e Peter J. Montiel.2008. "Monetary Policy Analysis in a Small Open Credit-Based Economy.” Open Economies Review 19: 423-455.

Arquete, Lílian Carla e Frederico Gonzaga Jayme-Jr. 2003. "Política monetária, preços e produto no Brasil (19942002): Uma aplicação de vetores auto-regressivos.” In Anais do XXXI Encontro da ANPEC.

Barth, Marvin J. e Valerie A. Ramey.2002. “The Cost Channel of Monetary Transmission.” In NBER Macroeconomics Annual 2001 (Ben S. Bernanke e Kenneth Rogoff, eds.) 16: 199-240, MIT Press.

Boivin, Jean e Marc Giannoni. 2006. “DSGE Models in a Data-Rich Environment.” NBER Working Paper Series.

Calvo, Guillermo A. 1983. "Staggered prices in a utility-maximizing framework." Journal of Monetary Economics 12: 383-398.

Carrillo, Julio Arturo, Patrick Fève, e Julien Matheron. 2007. "Monetary Policy Inertia or Persistent Shocks: A DSGE Analysis.” International Journal of Central Banking, 3: 1-38.

Carvalho, Fabia A. e Marcos Valli. 2011. "Fiscal Policy in Brazil through the Lens of an Estimated DSGE model." BCB Working Paper Series.

Cavalcanti, Marco A. F. H. e Luciano Vereda. 2011. "Propriedades Dinâmicas de um Modelo DSGE com Parametrizações Alternativas para o Brasil.” Texto para Discussão do IPEA.

Céspedes, Brisne, Elcyon Lima, e Alexis Maka. 2008."Monetary policy, inflation and the level of economic activity in Brazil after the Real Plan: stylized facts from SVAR models.” Revista Brasileira de Economia 62: 123-160.

Chowdhury, Ibrahim, Mathias Hoffmann, e Andreas Schabert.2006. "Inflation dynamics and the cost channel of monetary transmission.” European Economic Review 50: 995-1016.

Christiano, Lawrence J., Martin Eichenbaum, e Charles L. Evans. 2005. "Nominal Rigidities and the Dynamic Effects of a Shock to Monetary Policy.” Journal of Political Economy 113: 1-45.

Guimarães, Rafael Rockenbach da Silva e Sérgio Marley Modesto Monteiro. 2014. "Monetary Policy and Regional Output in Brazil." Revista Brasileira de Economia 68: 73-101.

De Fiori, Fiorella e OresteTristani. 2013. “Optimal Monetary Policy in a Model of the Credit Channel.” Economic Journal 123: 906-931.

Dedola, Luca e Francesco Lippi. 2005. "The monetary transmission mechanism: Evidence from the industries of five OECD countries.” European Economic Review 49: 1543-1569.

Fabiani, Silvia et al. 2006. "What Firms' Surveys Tell Us about Price-Setting Behavior in the Euro Area." International Journal of Central Banking 2: 3-47.

Fernandes, M. e J. Toro. 2005. "O mecanismo de transmissão monetária na economia brasileira pós-plano Real." Revista Brasileira de Economia 59: 5-32.

Gaiotti, Eugenio e Alessandro Secchi. 2006. "Is there a cost channel of monetary policy transmission? An investigation into the pricing behavior of 2000 firms." Journal of Money, Credit and Banking 38: 2013 - 2037.

Galí, Jordi, Mark Gertler, e J. David López-Salido. 2001. “European Inflation dynamics.” European Economic Review 45: 1237-1270. 
Henzel, Steffen, Oliver Hülsewig, Eric Mayer, e Timo Wollmershäuser. 2009. "The price puzzle revisited: Can the cost channel explain a rise in inflation after a monetary policy shock?" Journal of Macroeconomics 31: 268-289. Hülsewig, Oliver, Eric Mayer, e TimoWollmershäuser. 2009. "Bank behavior, incomplete interest rate pass-through, and the cost channel of monetary policy transmission." Economic Modelling 26: 1310-1327.

Kawamoto, Carlos Tadao e José Luis Oreiro. 2011. "Reavaliando a Existência de um Price Puzzle no Brasil: Implicações para o Regime de Metas de Inflação." In Anais do XXXIX Encontro Nacional de Economia.

Malikane, Christopher.2012. "Inflation dynamics and the cost channel in emerging markets." MPRA Paper.

Martins, Raphael. 2011. Cost-push channel of monetary policy: estimation and simulation. Master'sthesis, Faculdade de Economia, Administração e Contabilidade - USP.

Minella, André e Nelson Ferreira Souza-Sobrinho.2009. "Monetary Channels in Brazil through the Lens of a Semi-Structural Model.” BCB Working Papers Series.

Rabanal, P. e G. Schwartz. 2001. "Testing the effectiveness of the overnight interest rate as a monetary policy instrument." In Brazil: Selected Issues and Statistical Appendix (IMF, ed.), número 01/10 in IMF Country Report.

Rabanal, Pau. 2007. “Does inflation increase after a monetary policy tightening?” Journal of Economic Dynamics \& Control 31: 906-937.

Rabanal, Pau e Juan F. Rubio-Ramírez. 2007. “Comparing New Keynesian Models in the Euro Area: A Bayesian Approach.” Spanish Economic Review 10: 23-40.

Ravenna, Federico e Carl E. Walsh. 2006. "Optimal monetary policy with the cost channel.” Journal of Monetary Economics 53: 199-216.

Sales, A. e M. Tannuri-Pianto. 2005. "Mercado de reservas bancárias e identificação de choques de política monetária para o Brasil.” In Anais do XXVII Encontro Brasileiro de Econometria.

Sales, Adriana Soares e Maria Tannuri-Pianto. 2007. "Identification of Monetary Policy Shocks in the Brazilian Market for Bank Reserves." BCB Working Papers Series.

Santin, Rodrigo Ribeiro Martins. 2013. Análise da Política de Crédito do BNDES em um Modelo DSGE. Master'sthesis, Escola de Economia da Fundação Getúlio Vargas (FGV), São Paulo.

Santos, Fernando Genta. 2011. Ensaios sobre macroeconometria bayesiana aplicada. Master'sthesis, Faculdade de Economia, Administração e Contabilidade - Universidade de São Paulo.

Sato, Carolina Yumi. 2013. O canal de crédito na transmissão de política monetária: evidências para o Brasil. Master'sthesis, Escola de Economia da Fundação Getúlio Vargas (FGV), São Paulo.

Smets, Frank e Rafael Wouters., 2007. "Shocks and Frictions in US Business Cycles: A Bayesian DSGE Approach.” American Economic Review 97: 586-606.

Smets, Frank Rafael e RafWouters. 2003. "An Estimated Dynamic Stochastic General Equilibrium Model of the Euro Area.” Journal of the European Economic Association 1: 1123-1175.

Tillmann, Peter. 2008. "Do interest rates drive inflation dynamics? An analysis of the cost channel of monetary transmission." Journal of Economic Dynamics \& Control 32: 2723-2744.

Tovar, Camilo. 2009. "DSGE Models and Central Banks." Economics: The Open-Access, Open- Assessment E-Journal 3: 1-31.

Vasconcelos, Bruno Freitas Boynard e José Angelo Divino. 2012. "O desempenho recente da política monetária brasileira sob a ótica da modelagem DSGE." BCB Working Paper Series.

Vereda, Luciano e Marco A. F. H. Cavalcanti. 2010. "Modelo Dinâmico Estocástico de Equilíbrio Geral (DSGE) para a Economia Brasileira: Versão 1.” Texto para Discussão do IPEA. 


\section{Apêndice A - Testes de Especificação do Modelo VAR}

A Tabela 3 apresenta os resultados dos testes de especificação sobre os resíduos do modelo VAR estimado para a economia brasileira. Os resultados indicam que os resíduos são normalmente distribuídos e não autocorrelacionados.

Tabela 3 - Testes de Especificação do Modelo VAR

\begin{tabular}{|c|c|c|c|c|}
\hline & ste & Distribuição & Estatística de Teste & P-Valor \\
\hline \multicolumn{5}{|l|}{ Autocorrelação } \\
\hline & LM[1] & $\chi^{2}(25)$ & 19,07146 & 0,79368 \\
\hline & LM[4] & $\chi^{2}(100)$ & 109,67802 & 0,23878 \\
\hline \multicolumn{5}{|l|}{ Normalidade } \\
\hline & Doornik-Hansen & $\chi^{2}(10)$ & 8,55903 & 0,57440 \\
\hline
\end{tabular}

\section{Apêndice B - Análise de Robustez: Identificação}

A Figura 6 mostra os gráficos com o valor da função objetivo $(J)$ como função dos parâmetros estimados. Em cada gráfico, o parâmetro cujo valor foi modificado é indicado no topo. A curvatura de cada função objetivo é compatível com a determinação de um único ponto de mínimo no intervalo admitido para cada um dos parâmetros, então é possível concluir que a resposta da política monetária pode ser usada para identificar seus valores. 

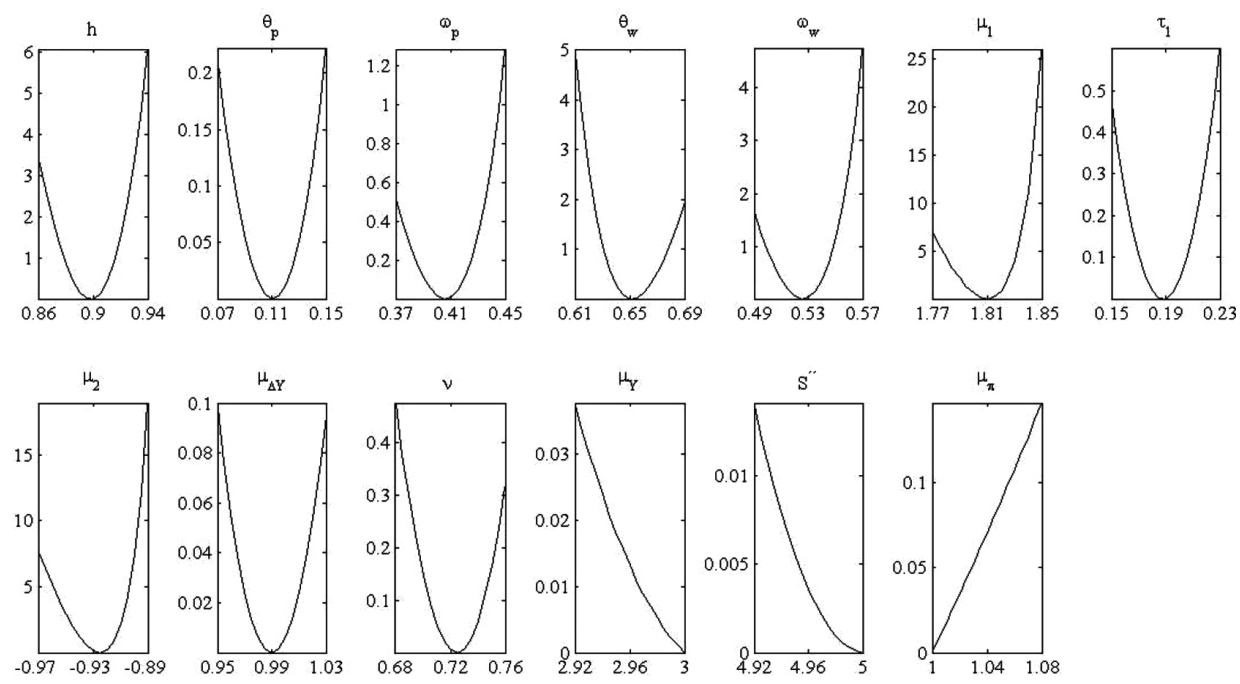

Figura 6 - Formato da Função Objetivo

Nota: o eixo vertical de cada gráfico mostra a diferença entre o valor da função objetivo $J$ e o valor da função objetivo que foi obtido no procedimento de minimização $(J=51,41)$. O eixo horizontal mostra o intervalo de variação de cada parâmetro. Em todos os casos, os parâmetros tiveram seus valores modificados respeitando variações de 0,005 .

Os gráficos na Figura 7 apresentam as densidades das estimativas para cada parâmetro definido no topo ao repetir o procedimento de estimação 500 vezes a partir de diferentes condições iniciais, que foram uniformemente sorteadas dentro do intervalo definido pelos limites usados para a otimização com restrição. Os resultados indicam que os valores obtidos na estimação apresentada inicialmente são similares às modas das distribuições posteriores, mesmo no caso dos parâmetros, cujas estimativas atingiram os limites dos intervalos. Assim, encontra-se mais uma evidência de que os parâmetros foram identificados apropriadamente. 

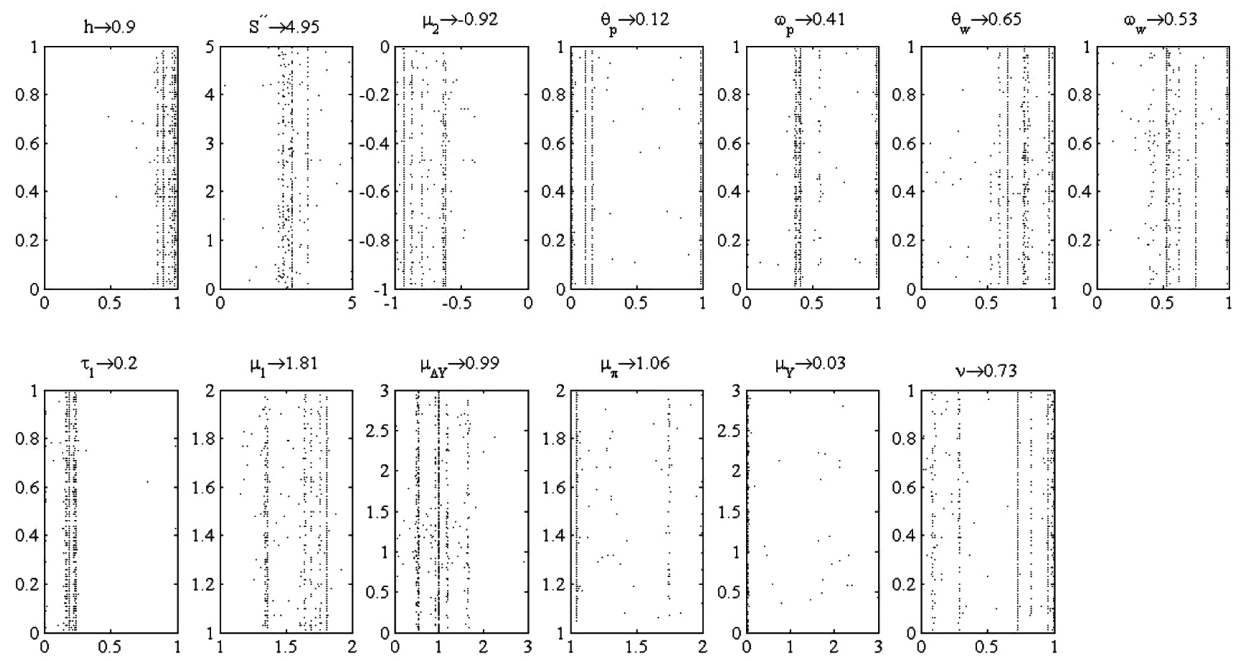

Figura 7 - Densidade das Estimativas

Nota: O eixo vertical de cada gráfico mostra os valores iniciais do parâmetro apresentado no topo. O eixo horizontal mostra o valor final do parâmetro obtido pelo processo de minimização da função objetivo.

\section{Apêndice C - Análise de Robustez: Variação dos Parâmetros Calibrados}

Figuras 8-14 mostram os resultados das estimações quando cada um dos parâmetros calibrados é alterado por vez. De modo geral, os parâmetros estimados variam pouco com os valores calibrados. Mudanças nos parâmetros da oferta de trabalho, $\eta$ e $\phi$, não afetam os parâmetros estimados significativamente. Se a taxa de depreciação, $\delta$, cresce, $\bar{S}^{\prime \prime}$ também cresce. $\grave{A}$ medida que $\sigma$ se aproxima de 3,0 , menor a resposta do banco central ao crescimento do gap do produto, $\mu_{\Delta \widehat{Y}}$, e maior é a proporção de firmas que dependem do capital de giro, $v$. Quanto maior a participação do capital, $\alpha$, maior $\bar{S}^{\prime \prime}$, e menores são os parâmetros que medem a rigidez de preços, $\theta_{p}$ e $v$. Se o inverso do poder de monopólio das firmas, $\epsilon$, aumenta, então $\bar{S}^{\prime \prime}$ aumenta e $v$ reduz. Por fim, quanto maior a proporção dos bancos que operam o crédito direcionado, $\tau_{2}$, maior o valor para $v$ e menor para $\theta_{p}$. 

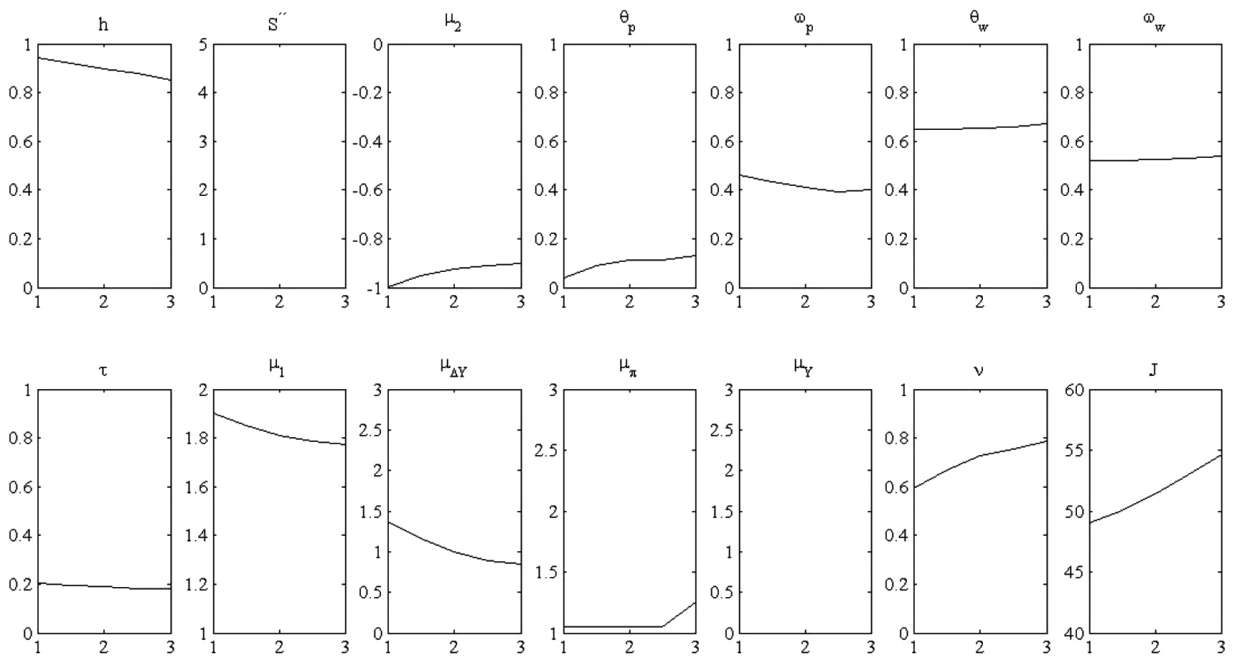

Figura 8 - Robustez das estimativas quanto a variações em $\sigma$
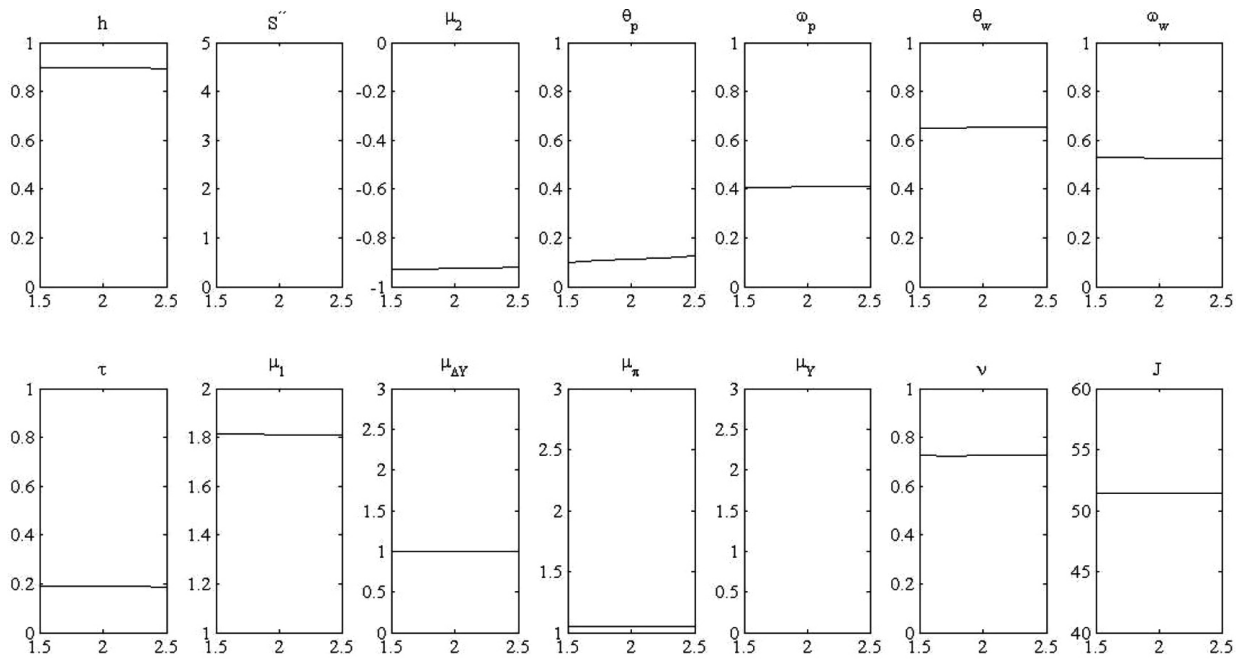

Figura 9 - Robustez das estimativas quanto a variações em $\eta$ 

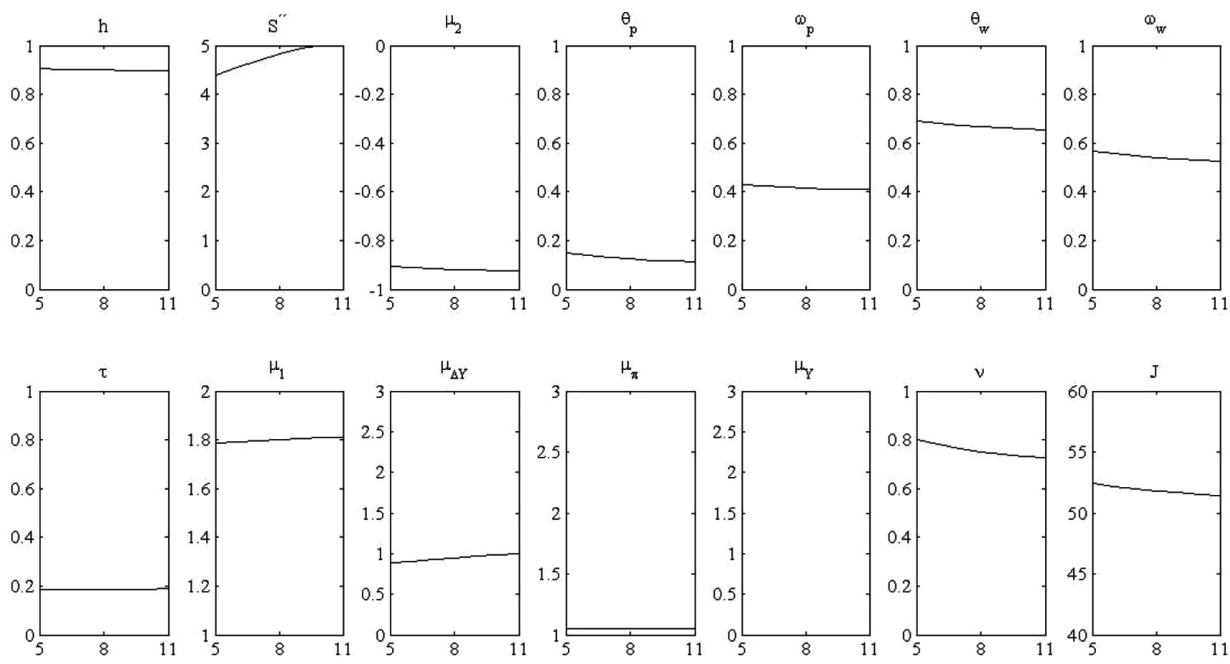

Figura 10 - Robustez das estimativas quanto a variações em $\varphi$
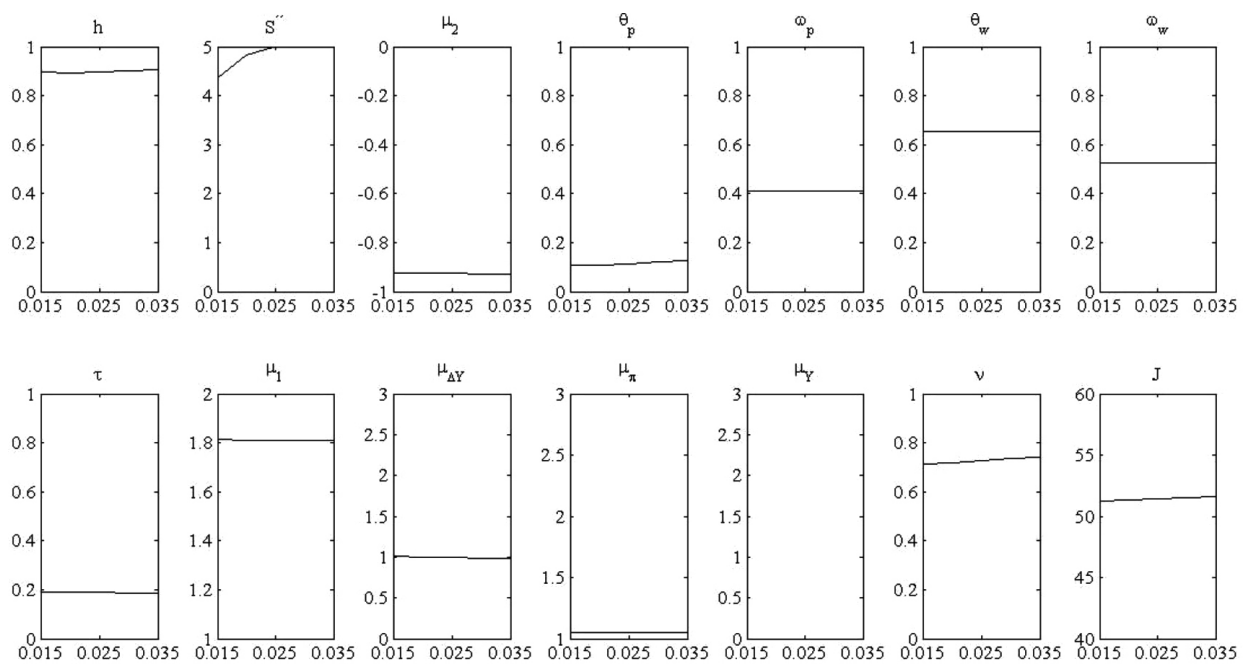

Figura 11 - Robustez das estimativas quanto a variações em $\delta$ 

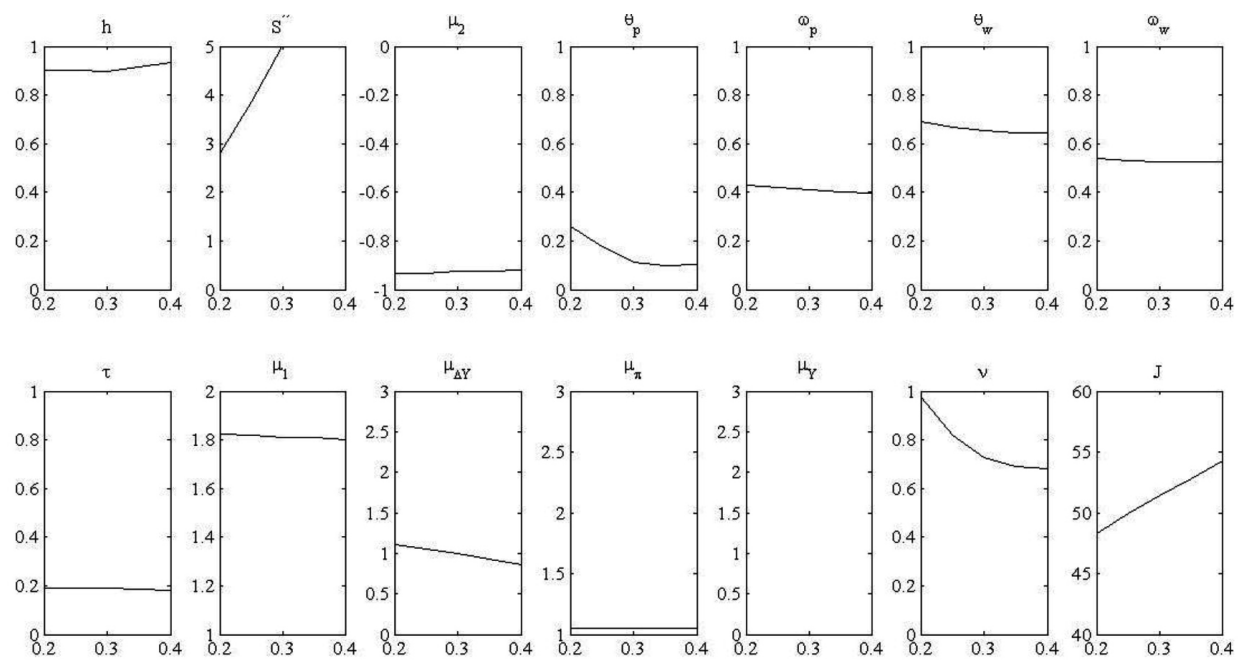

Figura 12 - Robustez das estimativas quanto a variações em $\alpha$
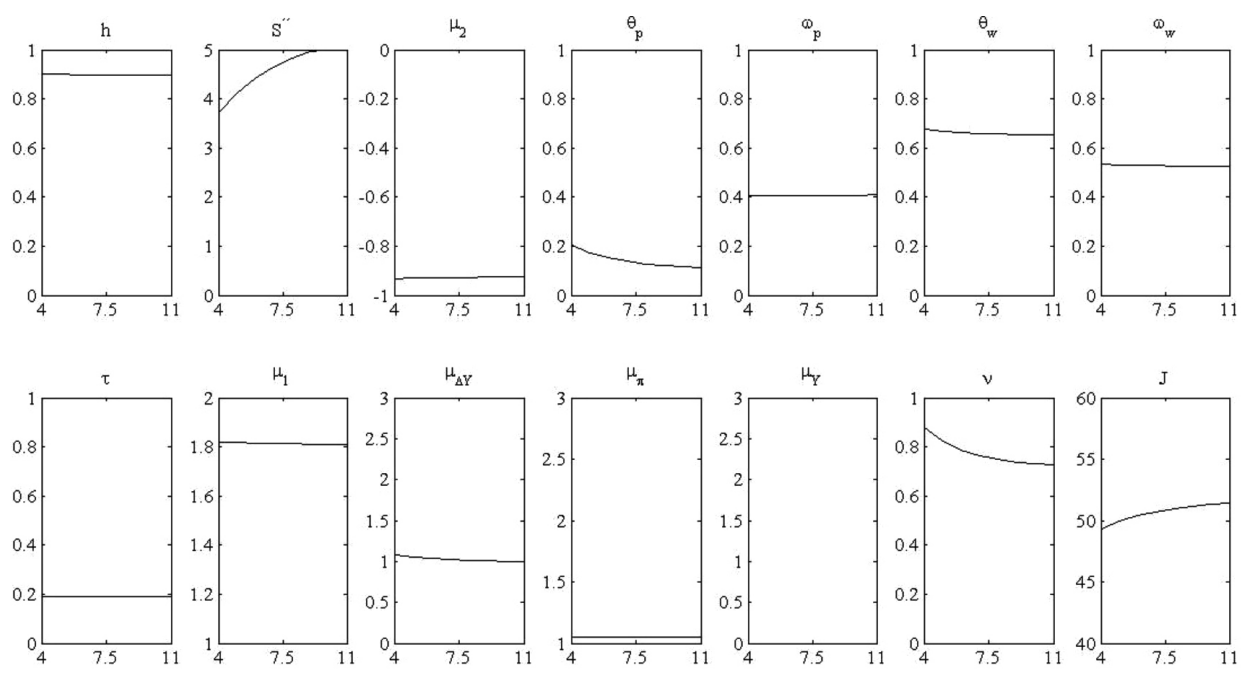

Figura 13 - Robustez das estimativas quanto a variações em $\epsilon$ 

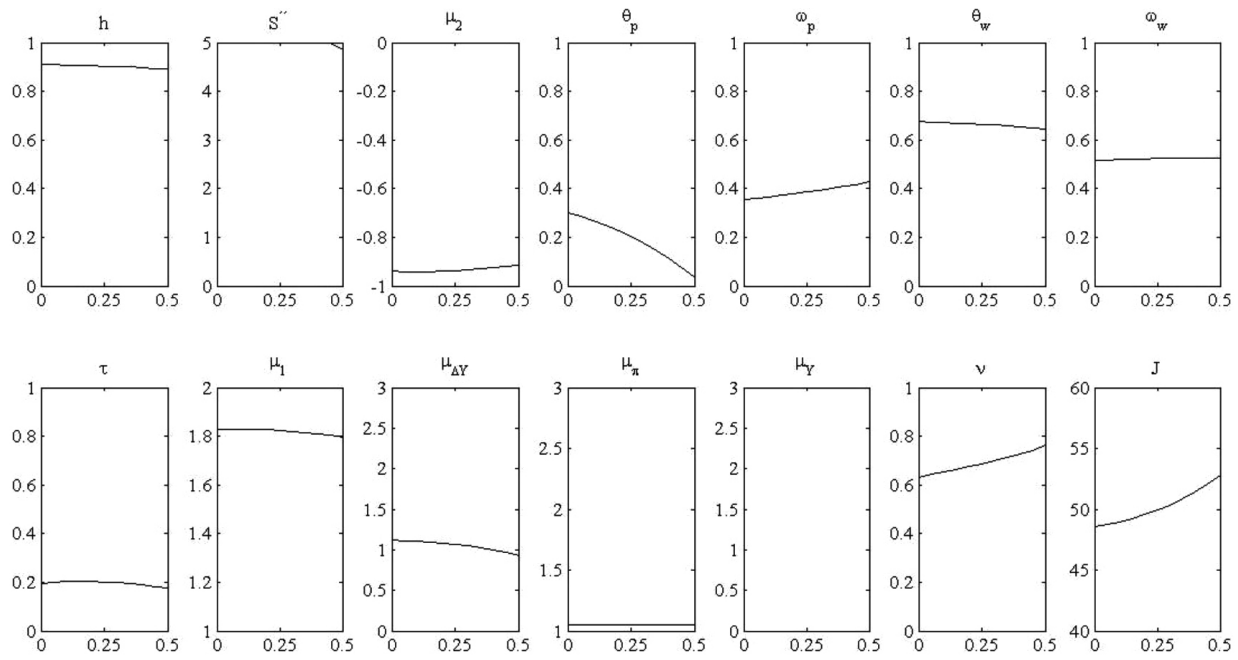

Figura 14 - Robustez das estimativas quanto a variações em $\tau_{2}$ 